\title{
'Candidatus Liberibacter asiaticus'-Encoded BCP Peroxiredoxin Suppresses Lipopolysaccharide-Mediated Defense Signaling and Nitrosative Stress In Planta
}

\author{
Mukesh Jain, ${ }^{1}$ Lulu Cai, ${ }^{1}$ lan Black, ${ }^{2}$ Parastoo Azadi, ${ }^{2}$ Russell W. Carlson, ${ }^{2}$ Kathryn M. Jones, ${ }^{3}$ and \\ Dean W. Gabriel ${ }^{1, \dagger}$ \\ ${ }^{1}$ Plant Pathology Department, University of Florida, Gainesville, FL 32611, U.S.A. \\ ${ }^{2}$ Complex Carbohydrate Research Center, University of Georgia, Athens, GA 30602, U.S.A. \\ ${ }^{3}$ Department of Biological Science, Florida State University, Tallahassee, FL 32306, U.S.A.
}

Accepted 28 November 2021.

\begin{abstract}
The lipopolysaccharides (LPS) of gram-negative bacteria trigger a nitrosative and oxidative burst in both animals and plants during pathogen invasion. Liberibacter crescens strain BT-1 is a surrogate for functional genomic studies of the uncultured pathogenic 'Candidatus Liberibacter' spp. that are associated with severe diseases such as citrus greening and potato zebra chip. Structural determination of $L$. crescens LPS revealed the presence of a very long chain fatty acid modification. $L$. crescens LPS pretreatment suppressed growth of Xanthomonas perforans on nonhost tobacco (Nicotiana benthamiana) and $X$. citri subsp. citri on host orange (Citrus sinensis), confirming bioactivity of $L$. crescens LPS in activation of systemic acquired resistance (SAR). L. crescens LPS elicited a rapid burst of nitric oxide (NO) in suspension cultured tobacco cells. Pharmacological inhibitor assays confirmed that arginine-utilizing NO synthase (NOS) activity was the primary source of NO generation elicited by $L$. crescens LPS. LPS treatment also resulted in biological markers of NO-mediated SAR activation, including an increase in the glutathione pool, callose deposition, and activation of the salicylic acid and azelaic acid (AzA) signaling networks. Transient expression of ' $\mathrm{Ca}$. L. asiaticus' bacterioferritin comigratory protein (BCP) peroxiredoxin in tobacco compromised AzA signaling, a prerequisite for LPS-triggered SAR. Western blot analyses revealed that ' $\mathrm{Ca}$. $\mathrm{L}$. asiaticus' $\mathrm{BCP}$ peroxiredoxin prevented peroxynitrite-mediated tyrosine nitration in tobacco. ' $\mathrm{Ca}$. $\mathrm{L}$. asiaticus' BCP peroxiredoxin (i) attenuates NO-mediated SAR signaling and (ii) scavenges peroxynitrite radicals, which would facilitate repetitive cycles of ' $\mathrm{Ca}$. $\mathrm{L}$. asiaticus' acquisition
\end{abstract}

${ }^{\dagger}$ Corresponding author: D. W. Gabriel; dgabr@ufl.edu

M. Jain and L. Cai contributed equally to this work.

Funding: This work was supported by the United States Department of Agriculture-National Institute of Food and Agriculture Specialty Crops Research Initiative (NIFA-SCRI) grant number 2016-70016-24844 (to D. W. Gabriel) and Chemical Sciences, Geosciences and Biosciences Division, Office of Basic Energy Sciences, U.S. Department of Energy grant number DE-SC0015662 (to P. Azadi).

*The $\boldsymbol{e}$-Xtra logo stands for "electronic extra" and indicates that a supplementary figure is published online.

The author(s) declare no conflict of interest. distributed under the CC BY-NC-ND 4.0 International license. and transmission by fecund psyllids throughout the limited flush period in citrus.

Keywords: bacterial pathogenesis, bacteria-plant symbiosis, citrus greening, effectors, elicitors, ethylene, huanglongbing, jasmonic acid, innate immunity, Liberibacter, lipid A, lipopolysaccharide, MAMPs, molecular signaling, nitric oxide, PAMPs, plant responses to pathogens, salicylic acid, systemic acquired resistance, zebra chip

The pathogenic gram-negative, $\alpha$-Proteobacteria 'Candidatus Liberibacter' spp. (order Rhizobiales) are uncultured, insecttransmitted, and phloem-limited plant pathogens most often associated with severe diseases but also causing mild or asymptomatic infections across several plant hosts (Gabriel et al. 2020). 'Candidatus Liberibacter solanaceraum' causes serious diseases in Solanaceae and Apiaceae crops, including zebra chip disease in potato, psyllid yellows in tomato, yellows decline in carrot, and vegetative disorders in fennel, celery, parsnip, and parsley (Monger and Jeffries 2018). Citrus greening, or huanglongbing (HLB), is arguably the single most destructive disease of citrus worldwide. HLB is caused by ' $\mathrm{Ca}$. L. asiaticus' in Asia and the Americas, ' $\mathrm{Ca}$. L. americanus' in Brazil, and ' $\mathrm{Ca}$. L. africanus' in Africa. They are primarily vectored among citrus and some other Rutaceae species by the Asian citrus psyllid Diaphorina citri Kuwayama (Sternorrhyncha: Psyllidae) (Gottwald 2010). Fecund psyllids acquire and transmit ' $\mathrm{Ca}$. L. asiaticus' repetitively to citrus while feeding on the young shoot flushes, resulting in a very short latency period (Lee et al. 2015). However, infected trees typically become symptomatic only after a long incubation period (sometimes spanning several years) (Chiyaka et al. 2012).

All attempts to achieve axenic growth (Merfa et al. 2019) or to complete Koch's postulates with any of the pathogenic ' $\mathrm{Ca}$. Liberibacter' spp. have failed to date, resulting, at best, in very low "titer" cocultures, with ' $C a$. L. asiaticus' present only as a minor component and detected only by PCR (Fujiwara et al. 2018; Ha et al. 2019; Molki et al. 2020). Absence of useful cocultures, let alone axenic cultures, has stymied contextual functional genomic studies of all pathogenic ' $\mathrm{Ca}$. Liberibacter' spp. However, several Sec-dependent (Clark et al. 2018, 2020; Pang et al. 2020; Zhang et al. 2020) as well as nonclassically secreted (Jain et al. 2015, 2018) proteins have been characterized that interfere with host defenses and promote bacterial colonization and HLB disease progression. By contrast, Liberibacter crescens strain BT-1 (GenBank accession NC_019907.1) has been axenically cultured (Leonard et al. 2012) but has no known 
insect or plant host. All Liberibacter spp. have undergone extensive genome reductions; BT-1 has a slightly larger genome size of $1.5 \mathrm{Mb}$ in comparison with the pathogenic ' $\mathrm{Ca}$. Liberibacter' spp. (all approximately $1.2 \mathrm{Mb}$ ). L. crescens has been developed into a surrogate model system for functional genomics for the uncultured pathogenic ' $C a$. Liberibacter' spp. (Jain et al. 2019a).

The outer membrane of gram-negative bacteria is composed primarily of lipopolysaccharide (LPS) consisting of three distinct structural and functional domains: the outermost O-antigenic polysaccharide consisting of a variable number of oligosaccharide repeats, the core oligosaccharide, and lipophilic lipid A. The highly conserved lipid A moiety is a mono- or bisphosphorylated disaccharide of glucosamine typically carrying four to seven acyl chains anchored within the outer leaflet of the bacterial outer membrane (Choma et al. 2017; Kawai and Akira 2011). Asymmetric distribution of LPS to the outer leaflet of the outer membrane and phospholipids to the inner leaflet is deemed essential for the outer membrane barrier function restricting in vivo permeability to host-derived toxins and antimicrobials (Malinverni and Silhavy 2009). Lipid A is a wellconserved pathogen-associated molecular pattern (PAMP) that is integral to elicitation of the primary animal and plant cellular defense responses known as pattern-triggered immunity (PTI). The onset of PTI is often marked by alkalinization of cell culture media, ion fluxes across host cell membranes, PATHOGENESIS-RELATED $(P R)$ gene expression, cell wall alteration, the oxidative burst, nitric oxide (NO) generation, and ethylene production (Ranf 2017; van der Burgh and Joosten 2019).

Perception of bacterial LPS in mammals results in exaggerated inflammation that can culminate in endotoxic shock during sepsis (Mogensen 2009). Bacterial LPS is perceived by transmembrane Toll-like receptor 4 and the coreceptors myeloid differentiation factor-2 and CD14 which, together, rapidly trigger an array of antimicrobial immune responses through the induction of various inflammatory cytokines, chemokines, type I interferons, cell adhesion molecules, and immunoreceptors. These proinflammatory responses lead to pathogen clearing, and orchestrate adaptive immune responses during disease progression and subsequent immune cognizance (Kawai and Akira 2011). Generation of high levels of NO via inducible nitric oxide synthase (iNOS or NOS2) activity is a hallmark feature of LPS presentation in mammals. NO is a universal and versatile signaling molecule and iNOSderived NO flux is a key arbitrator of immune signaling cascades in vivo (Thomas et al. 2015).

By contrast to mammalian systems, characterization of LPS perception in plants remains poorly understood. In the model plant Arabidopsis and other crucifers, a plant-specific bulb-type lectin S-DOMAIN-1-29 receptor kinase LIPOOLIGOSACCHARIDESPECIFIC REDUCED ELICITATION (LORE/SD1-29) elicited stereotypical PTI signaling upon treatment with Pseudomonas aeruginosa and Xanthomonas campestris LPS with native lipid A (Ranf et al. 2015; Silipo et al. 2008). However, perception of LPS and downstream signaling output were host specific due to the absence of LORE orthologs across all plant families other than Brassicaceae (Ranf et al. 2015). A lysine-motif containing CHITIN ELICITOR RECEPTOR KINASE-1, essential for the perception of the fungal PAMP chitin, was implicated in sensing LPS from $X$. oryzae pv. oryzae, P. aeruginosa, Escherichia coli, and Salmonella enterica in rice (Oryza sativa) but not in Arabidopsis (Desaki et al. 2018). Arabidopsis homologs of mammalian LPSbinding protein (LBP) and bactericidal- or permeability-increasing protein (BPI), AtLBP/BPI related-1 and -2, were found to interact with LPS from $E$. coli and $P$. aeruginos $a$ and regulate PTI-related gene expression (Iizasa et al. 2016, 2017).

Application of LPS to plants as a pretreatment can result in localized induced resistance (LIR) that can attenuate the virulence of plant pathogens and the hypersensitive programmed cell death response (HR) in response to effectors from avirulent plant pathogens (Dow et al. 2000; Erbs and Newman 2003). LPS-induced systemic acquired resistance (SAR) in plants is achieved through temporal and spatial modulation of NO, reactive nitrogen species, reactive oxygen species (ROS), and salicylic acid (SA) signaling networks. Metabolome analysis revealed accumulation of glycosylated signaling molecules; specifically, the nine-carbon dicarboxylic acid azelaic acid (AzA; 1,9-nonanedionic acid), SA, and methyl-salicylate (MeSA) in LPS-treated tobacco cells (Mhlongo et al. 2017). In Arabidopsis, treatment with $P$. aeruginosa LPS induced a biphasic oxidative burst. An initial weak and transient apoplastic ROS burst mediated via respiratory burst oxidase homolog $(\mathrm{RBOH})$ activity was followed by a stronger, longer-lasting second peak associated with the chloroplasts (Shang-Guan et al. 2018).

Spatially discrete NO fluxes are an important and ubiquitous signature of several physiological and developmental processes in plants and in host-pathogen interactions. NO-mediated posttranslational modifications of proteins such as cysteine $S$-nitrosylation (-NO addition) (Yun et al. 2011) and tyrosine nitration $\left(-\mathrm{NO}_{2}\right.$ addition to one of the two equivalent ortho-carbons of the tyrosine aromatic ring) (Castillo et al. 2015) both have significant impacts on cellular signaling events. In plants, NO is primarily formed via double monooxygenation of L-arginine to L-citrulline by a mammalian nitric oxide synthase (NOS)-like enzyme or reduction of nitrite to NO by a nitrate reductase (NR) (Astier et al. 2018). A plant NOS-like protein was purified for the first time from the green alga Ostreococcus tauri with similarity to the human enzyme in activity, architecture, and cofactor requirements (Foresi et al. 2010). Subsequent comparative phylogenetic and transcriptomic analyses of more than 1,000 land plants and 265 algal species revealed that the structurally conserved NOS-like proteins likely exist only in the photosynthetic algae (Jeandroz et al. 2016). Despite overwhelming evidence confirming the presence and pharmacological inhibition of mammalian NOS-like activity across several plant species, the search for a canonical NOS in higher plants has remained elusive thus far (Astier et al. 2018). Evidence also suggests that L-arginine-dependent NOS-like activity in plants is compartmentalized in peroxisomes and chloroplasts (Jasid et al. 2006).

The primary objective of this study was to gain insight into LPS-triggered PTI responses to pathogenic ' $C a$. Liberibacter' spp. in the absence of a cultured pathogen, by using purified LPS from $L$. crescens as a proxy. $L$. crescens LPS elicited generation of $\mathrm{NO}$ and induced defense-related gene expression in tobacco cell suspension cultured cells. Given that (i) the LPS biosynthetic pathways are well conserved between $L$. crescens and ' $C a$. L. asiaticus' and (ii) L. crescens LPS is bioactive, it is likely that similar NO-mediated defense responses would be elicited in citrus by ' $\mathrm{Ca}$. L. asiaticus' LPS. Lee et al. (2015) demonstrated ' $\mathrm{Ca}$. L. asiaticus' infectivity of citrus shoot flushes within 15 days due to repetitive acquisition and transmission cycles of ' $\mathrm{Ca}$. L. asiaticus' by fecund psyllids, causing rapid but asymptomatic spread of HLB in groves. This short latency period indicates an ineffective SAR in citrus. In this context, ' $\mathrm{Ca}$. L. asiaticus'-encoded and secreted bacterioferritin comigratory protein (BCP) peroxiredoxin (CLIBASIA_RS00445) (Jain et al. 2018, 2019b) was examined for a potential role in alleviation of LPS-induced nitrosative stress and subsequent suppression of PTI responses in planta.

\section{RESULTS}

\section{Structural characterization of LPS \\ from $L$. crescens strain BT-1.}

Purified lipid A from $L$. crescens has a traditional pentaacylated glucosamine disaccharide backbone lacking phosphate 
and containing two ester-linked C16:0 (3-OH) fatty acid (FA) residues, two amide-linked $\mathrm{C} 14: 0(3-\mathrm{OH})$ residues, and a very long chain fatty acid (VLCFA) (26-OHC28:0) (Fig. 1A) (Black et al. 2021). The L. crescens lipid A was structurally similar to the unusual VLCFA-modified lipid A of phylogenetically related Sinorhizobium meliloti (27-OHC28:0) and Brucella abortus [27-O( $\beta O m e C 4: 0) C 28: 0]$ (Ferguson et al. 2004). S. meliloti genes lpxXL (SMc04268 encoding Kdo2-lipid IVA lauroyltransferase, EC:2.3.1.241) and acpXL (SMc04278 encoding an acyl carrier protein) are required for the biosynthesis of VLCFA-modified lipid A. Homologs for both these genes are present in the genome of L. crescens (B488_RS04675 and B488_RS04700, respectively) but absent in all pathogenic (and uncultured) ' $C a$. Liberibacter' spp. Multiple attempts to inactivate $L$. crescens lpxXL and acpXL by marker interruption have remained unsuccessful to date (Jain et al. 2019a), leading to the speculation that VLCFA-modified lipid A is required for preserving the outer membrane barrier function required for axenic culture of $L$. crescens. All other structural genes of the Raetz pathway (Raetz et al. 2009) for lipid A biosynthesis are conserved in both $L$. crescens and ' $\mathrm{Ca}$. L. asiaticus', except for lpxM encoding lauroyl-Kdo2-lipid IVA myristoyltransferase (EC:2.3.1.243), which is missing from both (Supplementary Fig. S1). Quantitative real-time PCR (qRT-PCR) analysis revealed that all Raetz pathway genes of ' $\mathrm{Ca}$. L. asiaticus' were highly expressed in both citrus and Asian citrus psyllid as compared with the expression of chromosomal housekeeping gene peptide chain release factor 1 (prfA), indicating active LPS biosynthesis in both its plant and insect hosts (Fig. 1B). As expected, expression of BCP peroxiredoxin and flagellar basalbody rod protein gene $f g F$ was limited to citrus and psyllid hosts, respectively.

\section{L. crescens LPS elicited SAR in tobacco (Nicotiana benthamiana) and sweet orange (Citrus sinensis) leaves.}

$X$. perforans strain GEV-485 was syringe infiltrated into nonhost tobacco leaves for HR elicitation $\left(10^{8} \mathrm{CFU} \mathrm{m}{ }^{-1}\right)$ and for population growth analysis $\left(10^{5} \mathrm{CFU} \mathrm{ml^{-1 }}\right)$. Tobacco (Nicotiana benthamiana) leaves infiltrated with $X$. perforans developed typical HR symptoms within $24 \mathrm{~h}$, resulting in the death of infiltrated leaf tissue. However, pretreatment of tobacco leaves with L. crescens LPS $\left(100 \mu \mathrm{g} \mathrm{ml}^{-1}\right)$ prevented development of $X$. perforans-induced HR and resulted in only a generalized chlorosis of infiltrated leaf tissue (Fig. 2A). Likewise, in the pathogen growth assay, tobacco leaf tissue without LPS treatment developed chlorotic lesions at 3 days postinoculation (dpi), whereas yellowing was reduced even at $6 \mathrm{dpi}$ in the inoculated area that had been pretreated with LPS (Fig. 2B).

Consistent with the observations of symptoms, the $X$. perforans population was significantly reduced within the LPS-treated leaf tissue at $3 \mathrm{dpi}\left(5.3 \pm 2.3 \times 10^{4} \mathrm{CFU} \mathrm{cm} \mathrm{cm}^{-2}\right)$ and $6 \mathrm{dpi}(2.5 \pm$ $0.6 \times 10^{6} \mathrm{CFU} \mathrm{\textrm {cm } ^ { - 2 }}$ ) as compared with the control leaf tissue pretreated with only buffer at $3 \mathrm{dpi}\left(1.6 \pm 0.2 \times 10^{5} \mathrm{CFU} \mathrm{\textrm {cm } ^ { - 2 }}\right)$ and 6 dpi $\left(2.0 \pm 0.3 \times 10^{7} \mathrm{CFU} \mathrm{cm}^{-2}\right)$ (Fig. 2C). Similar suppression of $X$. perforans growth was also observed in tobacco leaves when the LPS pretreatment and bacterial inoculation
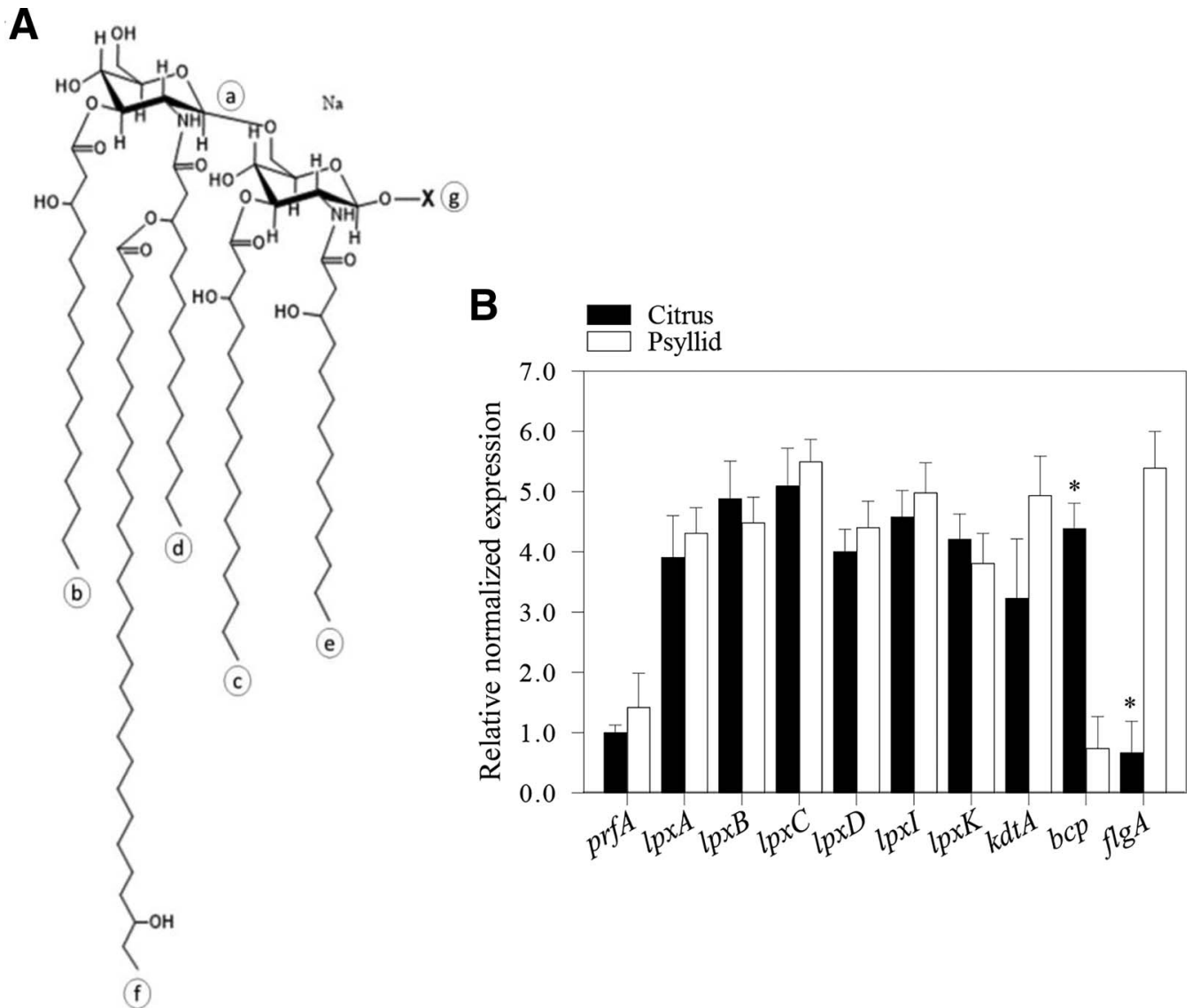

Fig. 1. A, Structure of Liberibacter crescens lipid A revealing (a) a traditional penta-acylated glucosamine disaccharide backbone; (b and c) two esterinked C16:0 (3-OH) fatty acid residues; ( $\mathrm{d}$ and e) two amide-linked $\mathrm{C} 14: 0(3-\mathrm{OH})$ residues; (f) a very long chain fatty acid $\mathrm{C} 28: 0(26-\mathrm{OH})$; and $(\mathrm{g})$ a 102-Da acid-labile substituent. B, Expression of 'Candidatus L. asiaticus' lipopolysaccharide biosynthesis genes in citrus and psyllid hosts. Relative transcript abundance of each gene was calibrated against expression of chromosomal gene prfA in ' $\mathrm{Ca}$. L. asiaticus'-infected citrus. Data presented are the means \pm standard error for three independent experiments with four replicates. Asterisks indicate significant differences between the treatment means (Student's $t$ test, $P \leq 0.05$ ). 
were performed on opposite sides of the tobacco leaf. LPS pretreatment (right side) significantly reduced the intracellular $X$. perforans population within the inoculated leaf tissue (left side) at $3 \mathrm{dpi}\left(6.3 \pm 2.3 \times 10^{4} \mathrm{CFU} \mathrm{cm}{ }^{-2}\right)$ and $6 \mathrm{dpi}(3.3 \pm 0.27 \times$ $10^{6} \mathrm{CFU} \mathrm{\textrm {cm } ^ { - 2 }}$ ) as compared with the buffer-treated (right side) leaf tissue at $3 \mathrm{dpi}\left(2.5 \pm 0.42 \times 10^{5} \mathrm{CFU} \mathrm{cm}^{-2}\right)$ and $6 \mathrm{dpi}(2.5 \pm$ $0.48 \times 10^{7} \mathrm{CFU} \mathrm{cm}^{-2}$ ) (Fig. 2D).

Using similar pretreatment methods, symptoms caused by the citrus canker pathogen $X$. citri subsp. citri strain 3213 inoculated on the left side of host sweet orange (Citrus sinensis) leaves
A

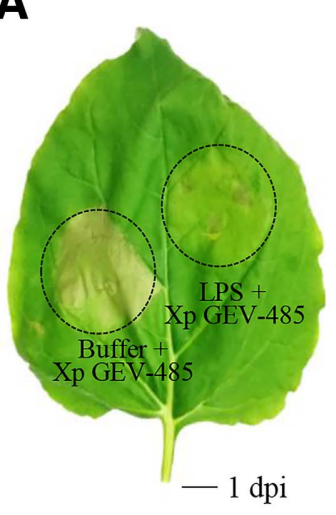

Xp GEV-485 $\left(10^{8} \mathrm{CFU} \mathrm{ml}^{-1}\right)$ buffer) treatment at the same site on non-host tobacco
B

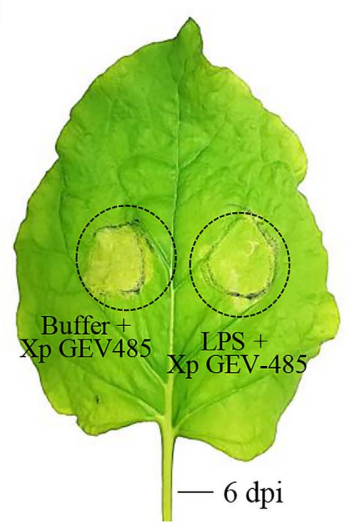

Xp GEV-485 (10 CFU ml-1) $^{-1}$ inoculation following LPS (or buffer) treatment at the same side on non-host tobacco

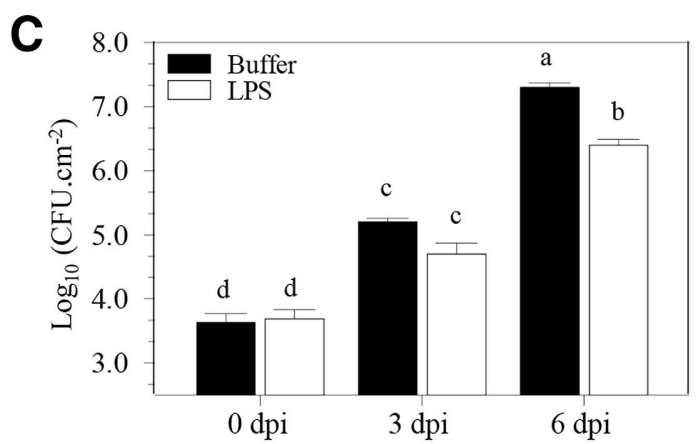

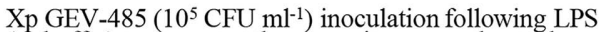
(or buffer) treatment at the same site on non-host tobacco

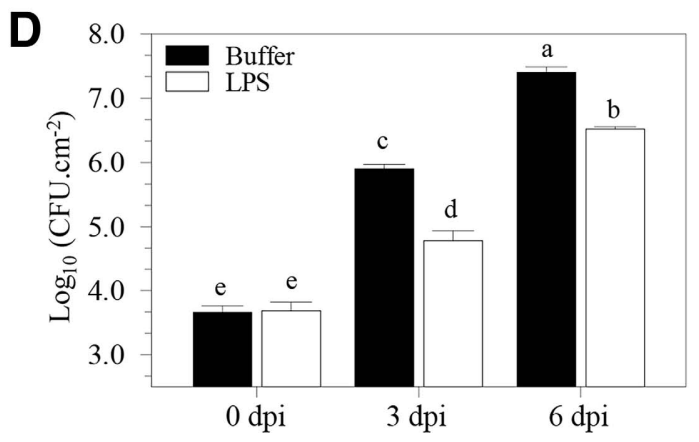

Xp GEV-485 $\left(10^{5} \mathrm{CFU} \mathrm{ml}^{-1}\right)$ inoculation (left-side) following LPS (or buffer) treatment (right-side) on non-host tobacco

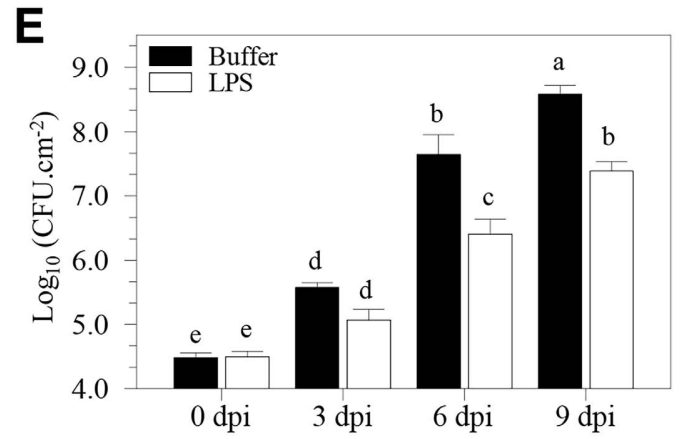

Xcc $3213\left(10^{6} \mathrm{CFU} \mathrm{ml}^{-1}\right)$ inoculation (left-side) following LPS (or buffer) treatment (right-side) on host sweet orange

F

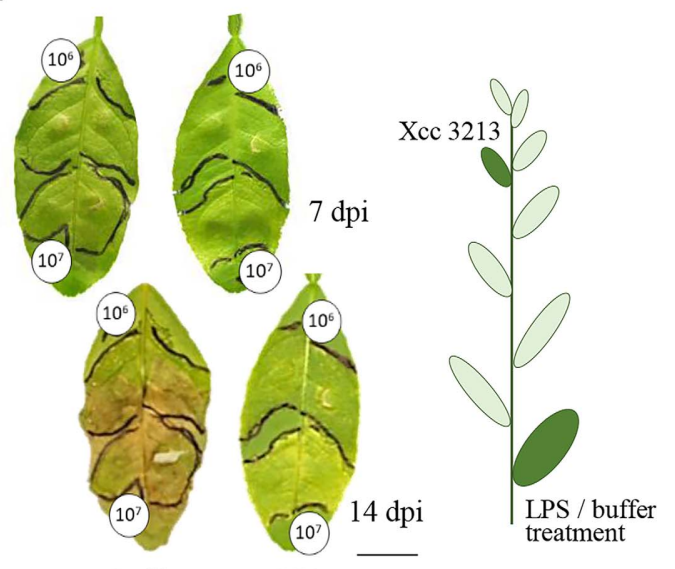

Xcc $3213\left(10^{6}\right.$ and $\left.10^{7} \mathrm{CFU} \mathrm{ml}^{-1}\right)$ inoculation ( +5 internodes) following LPS (or buffer) treatment on host sweet orange

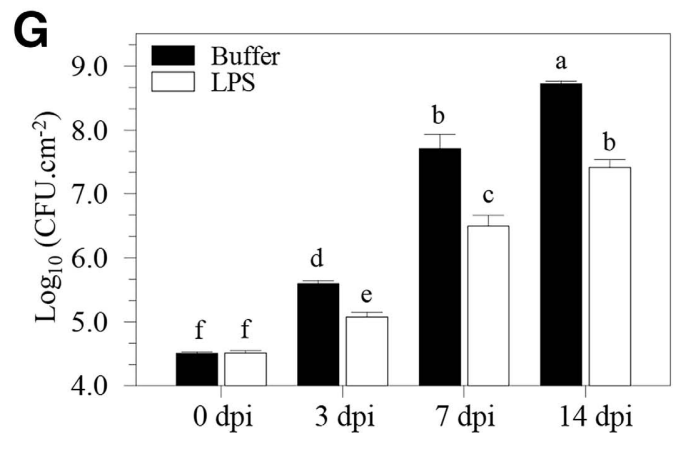

Xcc 3213 (106 CFU ml-1) inoculation ( +5 internodes) following LPS (or buffer) treatment on host sweet orange

Fig. 2. Liberibacter crescens lipopolysaccharide (LPS) potentiates localized induced resistance and systemic acquired resistance in planta. LPS pretreatment suppressed A, the nonhost hypersensitive programmed cell death response and B, chlorosis due to Xanthomonas perforans (Xp GEV-485) inoculated at the same site in Nicotiana benthamiana leaves. A, Xp GEV-485 inoculated at $10^{8} \mathrm{CFU} \mathrm{m}{ }^{-1}$ and leaf photographed 1 day postinfiltration (dpi). B, Xp GEV-485 inoculated at $10^{5} \mathrm{CFU} \mathrm{ml^{-1 }}$ and leaf photographed at 6 dpi. C and D, LPS pretreatment suppressed growth of Xp GEV-485 (starting inoculum of $10^{5} \mathrm{CFU} \mathrm{ml} l^{-1}$ ) measured at 0,3 , and $6 \mathrm{dpi}$ in tobacco leaves inoculated at the same site (C) or on opposite side (D). E, LPS pretreatment (right side) delayed growth of X. citri subsp. citri (Xcc 3213) following inoculation (left side) on host Citrus sinensis leaves. Xcc 3213 was inoculated at $10^{6} \mathrm{CFU} \mathrm{ml} \mathrm{m}^{-1}$ and pathogen growth was measured at $0,3,6$, and 9 dpi. F, Suppression of canker symptoms on Xcc 3213-inoculated sweet orange leaves (starting inoculum of $10^{6}$ or $10^{7} \mathrm{CFU} \mathrm{ml} l^{-1}$, as indicated) five internodes above the LPS pretreatment site. G, LPS suppressed intracellular growth of Xcc 3213 (starting inoculum of $10^{6} \mathrm{CFU} \mathrm{m}{ }^{-1}$ ) in the inoculated sweet orange leaves five internodes above the LPS pretreatment site. Tobacco and sweet orange leaves were pretreated with either buffer $\left(2.5 \mathrm{mM} \mathrm{MgCl}_{2}\right.$ and $\left.1 \mathrm{mM} \mathrm{CaCl}_{2}\right)$ or LPS $\left(100 \mu \mathrm{g} \mathrm{ml}^{-1}\right.$ in buffer). Data presented are the means $( \pm$ standard error) for three independent experiments. Treatment means followed by different letters are significantly different based on Tukey's honestly significant difference test $(P \leq 0.05)$. Size bars $=1 \mathrm{~cm}(\mathrm{~A}, \mathrm{~B}$, and $\mathrm{F})$. 
were delayed by pretreating the right side of the leaves with $L$. crescens LPS. LPS pretreatment reduced water soaking and subsequent hyperplasia on sweet orange leaves inoculated with $X$. citri subsp. citri as compared with the control leaves treated with buffer alone (data not shown). Intracellular growth of $X$. citri subsp. citri on these sweet orange leaves was suppressed at 6 dpi $\left(2.83 \pm 0.16 \times 10^{6} \mathrm{CFU} \mathrm{cm}^{-2}\right)$ and $9 \mathrm{dpi}(2.53 \pm 0.87 \times$

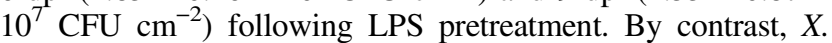
citri subsp. citri growth was significantly higher in mock-

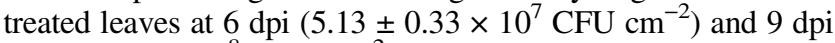
$\left(3.93 \pm 0.12 \times 10^{8} \mathrm{CFU} \mathrm{cm}^{-2}\right)$ (Fig. 2E).

Systemic suppression of canker symptoms (Fig. 2F) and pathogen growth (Fig. 2G) on host leaves were also observed at long distance. Intracellular growth of $X$. citri subsp. citri on sweet orange leaves was significantly reduced at $3 \mathrm{dpi}(1.20 \pm$ $\left.0.21 \times 10^{5} \mathrm{CFU} \mathrm{cm}^{-2}\right), 7 \mathrm{dpi}\left(3.303 \pm 0.13 \times 10^{6} \mathrm{CFU} \mathrm{cm}^{-2}\right)$,

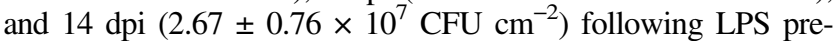
treatment of leaves five internodes below. By contrast with the controls, $X$. citri subsp. citri growth at 3 dpi $\left(3.9 \pm 0.42 \times 10^{5}\right.$ $\left.\mathrm{CFU} \mathrm{cm}{ }^{-2}\right), 7 \mathrm{dpi}\left(5.57 \pm 0.28 \times 10^{7} \mathrm{CFU} \mathrm{cm}^{-2}\right)$, and $14 \mathrm{dpi}$ $\left(5.23 \pm 0.51 \times 10^{8} \mathrm{CFU} \mathrm{\textrm {cm } ^ { - 2 }}\right)$ was higher in plants pretreated with buffer alone.

Taken together, these data clearly confirmed the bioactivity of L. crescens LPS in eliciting both short-distance (LIR) and longdistance (SAR) defense signaling cascades against pathogen infection of both hosts and nonhosts.

\section{L. crescens LPS induced a strong NO burst in tobacco suspension cultured cells.}

In plant cells, NR and NOS are two key enzymatic routes for the biosynthesis of $\mathrm{NO}$, even though a canonical mammalian NOS-like enzyme has not been purified from higher plants. We examined the potential of $L$. crescens LPS to induce a NO burst in suspension-cultured tobacco cells. Pharmacological inhibitors of NOS and NR activity were used here to characterize the enzymatic mechanism of NO production in tobacco suspension cultures.

3-Amino,4-aminomethyl-2', 7'-difluorescein diacetate (DAFFM DA) was used as a specific fluorescent sensor for NO radicals, because it is readily permeable across cell membranes and, once internalized in cytoplasm, undergoes a rapid 160-fold increase in fluorescence quantum yield after reacting with NO-derived species such as $\mathrm{N}_{2} \mathrm{O}_{3}$ (Mur et al. 2013). A rapid burst of green florescence was observed in tobacco suspension cultured cells preloaded with DAF-FM DA $(10 \mu \mathrm{M})$ following treatment with purified L. crescens LPS $\left(100 \mu \mathrm{g} \mathrm{ml}^{-1}\right)$ (Fig. 3A). The LPS-triggered NO burst in tobacco cells was significantly attenuated in the presence of the NOS inhibitors $N_{\omega}$-nitro-L-arginine (L-NNA; $300 \mathrm{mM}$ ) and $N_{\omega}$-nitro-L-argininemethyl ester (L-NAME; $300 \mathrm{mM}$ ), and the NO scavenger 2-(4carboxyphenyl)-4,4,5,5-tetramethylimidazoline-1-oxyl-3-oxide (cPTIO; $100 \mathrm{mM}$ ). However, the typical increase in DAF-FM florescence in response to LPS treatment was not significantly impacted by known inhibitors of NR activity $(100 \mu \mathrm{M}$ sodium azide or sodium tungstate), implying that LPS-triggered NO synthesis is not catalyzed through NR activity (Fig. 3B). NO induction data in LPS-treated tobacco cells were also quantitatively corroborated using a microplate assay (Fig. 3C).

To help confirm the enzymatic source of the NO burst, LPStreated cell extracts were assayed for NOS-like enzyme activity using a conventional arginine-utilization assay (Fig. 3D). Basal NOS-like enzyme activity $\left(2.9 \pm 0.5 \mathrm{mU} \mathrm{mg}^{-1}\right.$ of protein) increased threefold after $20 \mathrm{~min}$ in LPS-treated tobacco cells $\left(8.7 \pm 0.9 \mathrm{mU} \mathrm{mg}^{-1}\right.$ of protein) and the enzyme activity was found to be strongly inhibited by L-NNA and L-NAME $(2.2 \pm$ 0.8 and $2.0 \pm 0.9 \mathrm{mU} \mathrm{mg}^{-1}$ of protein, respectively). As expected, the LPS-induced increase in the NOS-like activity was insensitive to inhibition by cPTIO. However, both sodium azide and sodium tungstate only partially inhibited NOS-like activity $(P<0.05)$. These results confirmed that the PAMP activity of $L$. crescens LPS was manifested primarily by NOS-mediated NO production.

\section{L. crescens LPS elicited NO-mediated defense responses and SAR signaling in tobacco.}

The relative content of low-molecular-weight thiol glutathione ( $\gamma$-glutamylcysteinylglycine) in its reduced (GSH) and oxidized (glutathione disulfide [GSSG]) forms is indicative of cellular antioxidant buffering capacity and the intracellular redox status. $S$-nitrosylation of GSH to form $S$-nitrosoglutathione (GSNO) and subsequent GSNO turnover by $S$-nitrosoglutathione reductase (GSNOR) activity represents the primary mechanism facilitating NO storage, phloem transport, and signal transduction (Astier et al. 2018). Exposure of tobacco suspension cultured cells to $L$. crescens LPS resulted in a 1.6-fold increase in GSH as compared with untreated control cells $(175.9 \pm 24.5$ and $108.4 \pm$ $19.8 \mathrm{nmol} \mathrm{mg}^{-1}$ of protein, respectively) (Fig. 4A) accompanied by an elevated $\mathrm{GSH} /(\mathrm{GSH}+\mathrm{GSSG})$ ratio (Fig. 4B). This increase in GSH content as well as the GSH/(GSH+GSSG) ratio observed in response to LPS exposure were both sensitive to the NOS inhibitors (L-NNA and L-NAME) and NO scavenger (cPTIO), indicating that these changes in redox capacity were mediated through the NO burst. Additionally, transcriptional activation of NbGSNOR in L. crescens LPS-treated tobacco cells appeared to be in response to the NOS-mediated NO burst (Fig. 4C). qRT-PCR data showed a significant 4.3 -fold increase in NbGSNOR transcript abundance in LPS-treated tobacco cells that was inhibited in the presence of L-NNA, L-NAME, and cPTIO.

Callose deposition and the expression of callose synthase genes were also investigated in $L$. crescens LPS-infiltrated tobacco leaves. Callose deposition in LPS-infiltrated leaves confirmed the PAMP activity of $L$. crescens LPS (Fig. 4D, $i v$ ). Transcription of the callose synthase genes $\mathrm{NbCalS1}$ and $\mathrm{NbCalS12}$ was significantly upregulated in LPS-infiltrated leaves as compared with the untreated control samples (Fig. 4E). Moreover, transcriptional upregulation of $\mathrm{NbCalS1}$ and $\mathrm{NbCalS12}$ was inhibited by cotreatment with cPTIO indicating NO-mediated regulation of callose deposition. No significant differences were

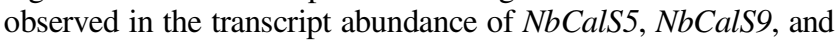
$\mathrm{NbCalS10}$ between control and LPS-treated leaf tissue. Among several callose synthase genes annotated in the Arabidopsis genome, only AtCalS1 and AtCalS12 have previously been shown to be transcriptionally regulated by NO (Dong et al. 2008).

Transcriptional analyses of tobacco suspension cultured cells exposed to L. crescens LPS revealed significant upregulation of SA biosynthesis and signaling genes isochorismate synthase 1 (NbICS), NON-EXPRESSOR of PATHOGENESIS-RELATED GENES 1 (NbNPRl), and SA-binding protein 2 (NbSABP2). Likewise, high abundance of $P R$ gene $N b P R-1$ transcripts in LPS-treated tobacco cells indicated a strong SAR response to $L$. crescens LPS (Fig. 5A). However, transcript abundance of ROSresponsive plasma membrane-bound $\beta$-nicotinamide adenine dinucleotide phosphate (NADPH) oxidase (RBOH B; NbRbohB) was not significantly different between untreated control and LPS-treated cells. AzA is generated via peroxidative fragmentation of 18-carbon FAs carrying a double bond at the nine-carbon position and constitutes an essential SAR signal operating in parallel to SA (Yu et al. 2013). Transcript levels of AzA-mediated signaling components - namely, the lipid transfer protein (LTP) gene DEFECTIVE IN INDUCED RESISTANCE-1 (NbDIRl), LTP-like protein gene AzA INSENSITIVE-1 (NbAZII), and glycerol-3-phosphate (G3P) dehydrogenase (NbG3PD) - were also significantly higher in LPS-treated tobacco cells (Fig. 5B). Pipecolic acid (Pip), a nonproteinaceous lysine catabolite, functions 
A
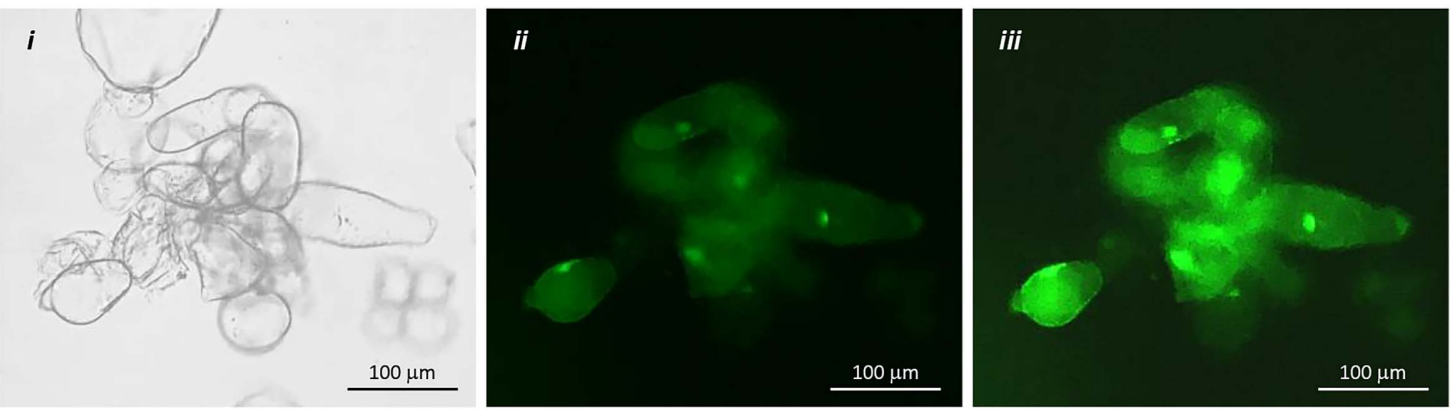

B
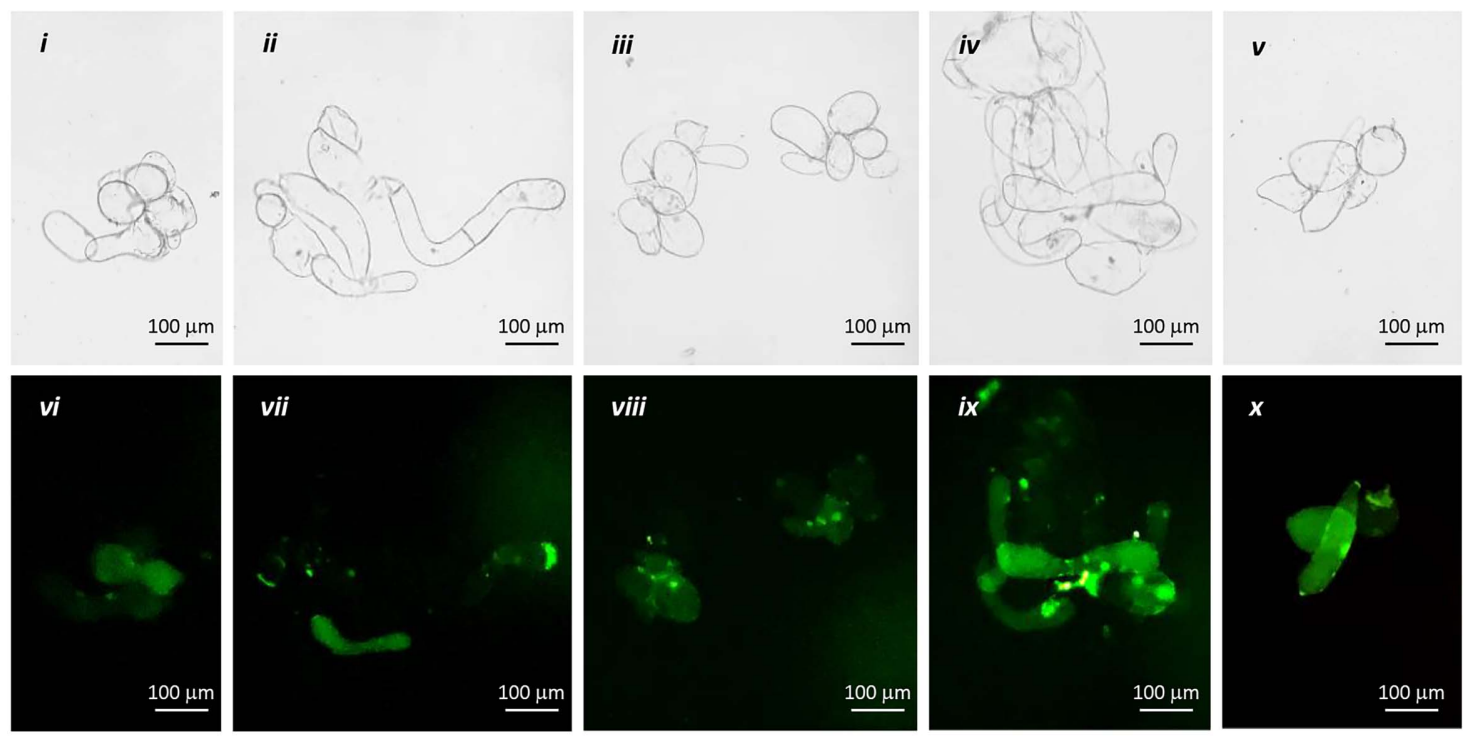

C

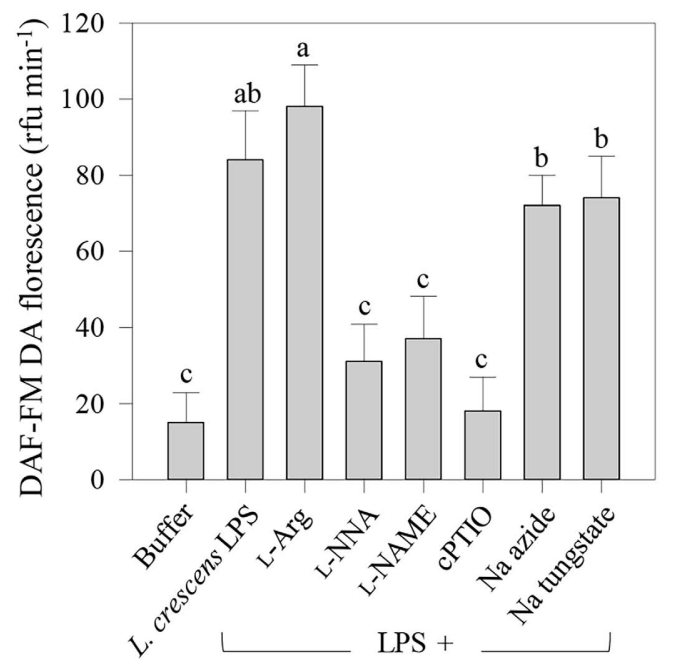

D

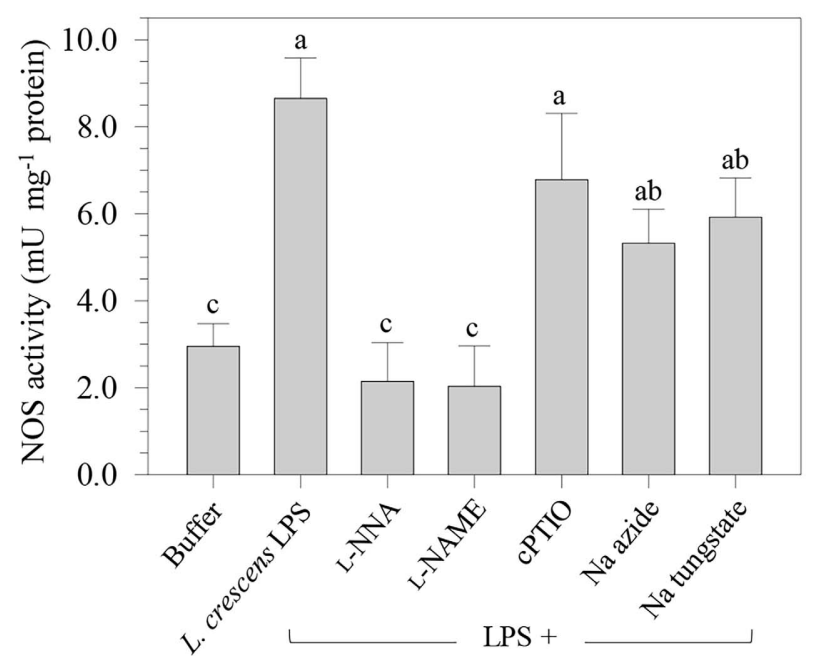

Fig. 3. Liberibacter crescens lipopolysaccharides (LPS) elicited an Arg-utilizing nitric oxide (NO) burst in Nicotiana benthamiana suspension cultured cells. A, Time course of the NO burst as detected by intracellular 3-amino,4-aminomethyl-2', $7^{\prime}$-difluorescein diacetate (DAF-FM DA) fluorescence in a tobacco cell cluster after LPS stimulation; $i$ : brightfield; $i i$ and iii: florescence imaging after 5 and 15 min of LPS treatment, respectively. B, Effect of mammalian NO synthase (NOS) inhibitors and NO scavenger on LPS-induced NO levels. For each treatment, fluorescence and bright-field images are shown after 15 min of LPS treatment ( $i$ and vi: $N_{\omega}$-nitro-L-arginine [L-NNA]; ii and vii: $N_{\omega}$-nitro-L-arginine-methyl ester [L-NAME]; iii and viii: 2-(4-carboxyphenyl)-4,4,5,5-tetramethylimidazoline-1-oxyl-3-oxide [cPTIO]; $i v$ and $i x$ : sodium [Na] azide; and $v$ and $x$ : Na tungstate). Quantification of C, NO-related DAF-FM DA fluorescence and D, NOS-like enzymatic activity in LPS-treated tobacco suspension cultured cells. Tobacco cells were preloaded with DAF-FM DA $(10 \mu \mathrm{M})$ for $20 \mathrm{~min}$ (A to C) and treated with either buffer $\left(2.5 \mathrm{mM} \mathrm{MgCl}{ }_{2}\right.$ and $\left.1 \mathrm{mM} \mathrm{CaCl}_{2}\right), \mathrm{LPS}$ alone $\left(100 \mu \mathrm{g} \mathrm{ml}^{-1}\right.$ in buffer), or LPS in combination with L-Arg $(500 \mathrm{mM})$, L-NNA $(300 \mathrm{mM})$, L-NAME $(300 \mathrm{mM})$, cPTIO (100 mM), Na azide (100 $\mu$ M), or Na tungstate $(100 \mu \mathrm{M})$ for $15 \mathrm{~min}$. DAF-FM DA florescence was monitored at $\lambda_{\mathrm{ex} / \mathrm{em}}=495 / 515 \mathrm{~nm}$. One unit of NOS activity is defined as the amount of enzyme required to yield $1 \mu \mathrm{mol}$ of $\mathrm{NO}$ produced per minute at $37^{\circ} \mathrm{C}$ under the assay conditions. Data presented are the means ( \pm standard error) for three independent experiments with 10 replicates (C) and 4 replicates (D). Treatment means followed by different letters are significantly different based on Tukey's honestly significant difference test $(P \leq 0.05)$. 
primarily upstream of the linear NO-ROS-AzA-G3P branch of the SAR pathway by modulating levels of NO, ROS, and G3P (Wang et al. 2018). Transcriptional upregulation of lysine aminotransferase gene AGD2-LIKE DEFENSE RESPONSE PROTEIN 1 (NbALD1), ornithine cyclodeaminase gene SAR-DEFICIENT 4 (NbSARD4), and FLAVIN-DEPENDENT MONOOXYGENASE 1 (NbFMO1) in LPS-treated tobacco cells (Fig. 5C) corroborated biosynthesis of N-hydroxypipecolic acid (NHP) from Pip, a critical metabolic phloem-mobile regulator of SAR.

The data presented above clearly confirmed that $L$. crescens LPS presentation results in the establishment of local as well as systemic immunity via accumulation of SA and the priming components of SAR; namely, AzA and NHP.

\section{AzA-mediated SAR signaling in tobacco is suppressed by ' $\mathrm{Ca}$. L. asiaticus'-secreted BCP peroxiredoxin.}

The 'Ca. L. asiaticus'-encoded 1-Cys BCP peroxiredoxin was previously characterized as a potential pathogenicity effector mitigating peroxidative damage to free and membrane-bound lipids (Jain et al. 2018, 2019b). NO and ROS both cause hydrolysis of 18-carbon FAs, thereby contributing to the biosynthesis of the AzA. Therefore, the effect of $L$. crescens LPS on the expression levels of AzA-signaling genes in tobacco leaves was examined following Agrobacterium-mediated transient expression of $\beta$-glucuronidase (GUS) or BCP peroxiredoxin from the binary plasmids pCAMBIA2301 (CaMV35S::uidA) or pAMB004 (CaMV35S::Lasbcp), respectively. As compared with leaf tissue transiently expressing GUS, significant upregulation of $N b A Z I 1, N b D I R 1$, and $N b G 3 P D$ was discernible in wild-type leaf tissue infiltrated with $L$. crescens LPS as well as in leaves transiently expressing GUS and coinfiltrated with LPS at 4 dpi (Fig. 6A). However, NbAZI1, NbDIRI, and NbG3PD were transcriptionally downregulated in leaf tissue transiently expressing ' $\mathrm{Ca}$. L. asiaticus' BCP peroxiredoxin and coinfiltrated with LPS as compared with wild-type leaves or GUS-expressing leaves treated with LPS.
A

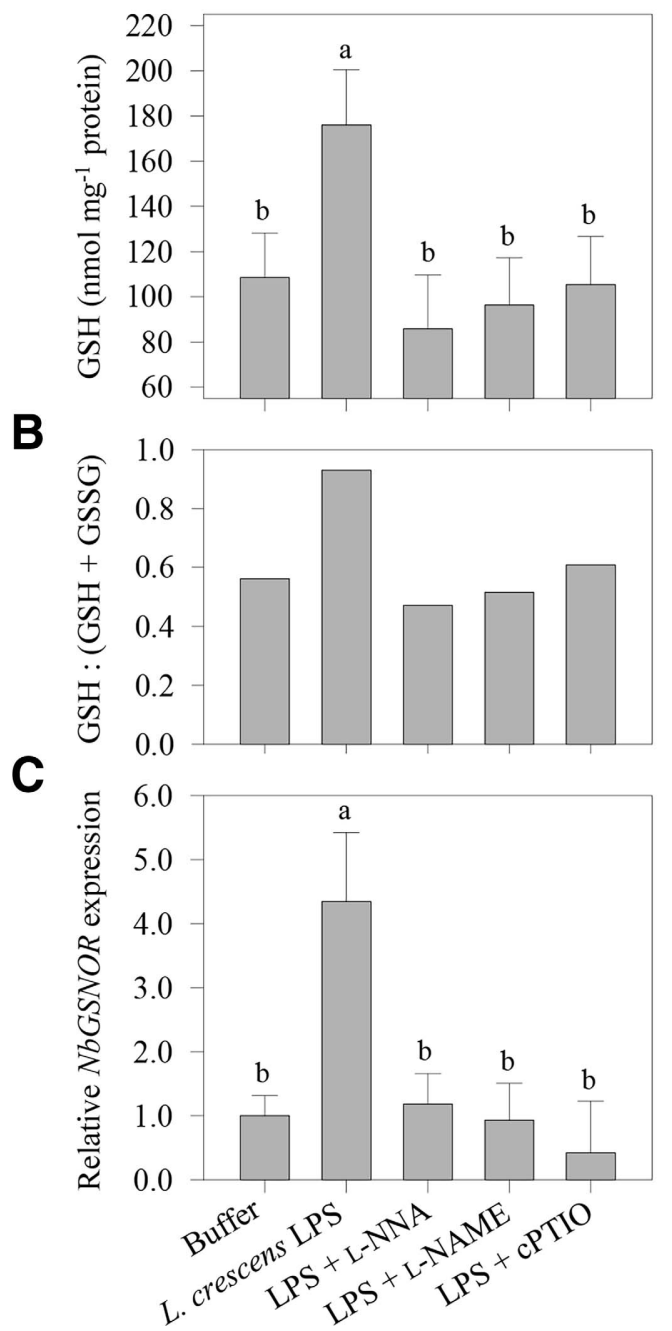

D
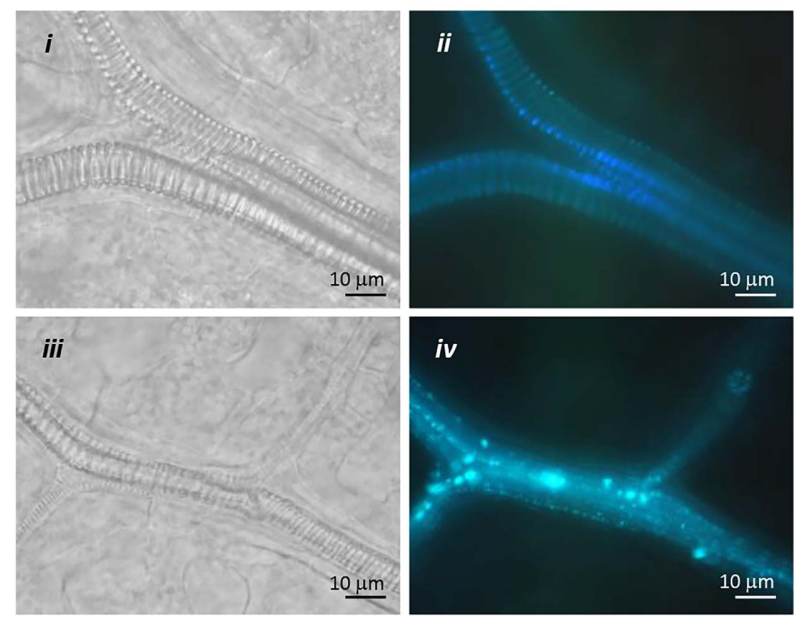

E

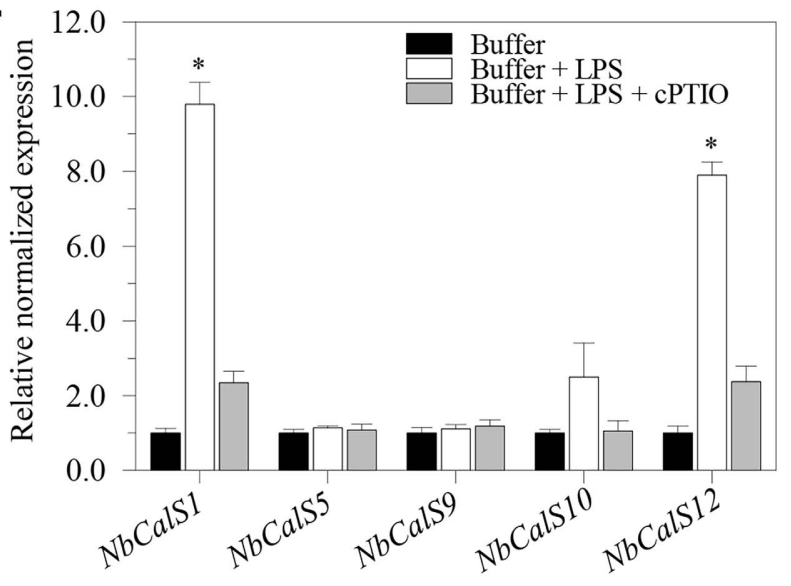

Fig. 4. Liberibacter crescens lipopolysaccharides (LPS) elicited nitric oxide (NO)-mediated defense responses and systemic acquired resistance (SAR) signaling in Nicotiana benthamiana. NO-mediated increases in A, total glutathione (GSH) content; B, GSH/(GSH + glutathione disulfide [GSSG]) ratio; and C, transcriptional activation of $S$-nitrosoglutathione reductase $(N b G S N O R)$ in $L$. crescens LPS-treated tobacco suspension cultured cells. Tobacco cells were treated with LPS (100 $\left.\mathrm{g} \mathrm{ml}^{-1}\right), N_{\omega}$-nitro-L-arginine (L-NNA; $\left.300 \mathrm{mM}\right), N_{\omega}$-nitro-L-arginine-methyl ester (L-NAME; 300 mM), and 2-(4-carboxyphenyl)-4,4,5,5-tetramethylimidazoline-1-oxyl-3-oxide (cPTIO; $100 \mathrm{mM}$ ) for 10 to $12 \mathrm{~h} \mathrm{D}$, Callose deposition and E, expression of callose synthase (NbCalS) genes in LPSinfiltrated tobacco leaves. Callose deposition (D) was visualized by UV epifluorescence in tobacco leaves $48 \mathrm{~h}$ after infiltration of buffer ( $i$ and $i i$ : $2.5 \mathrm{mM}$ $\mathrm{MgCl}_{2}$ and $1 \mathrm{mM} \mathrm{CaCl}_{2}$ ) or LPS ( $i i i$ and $i v: 100 \mu \mathrm{g} \mathrm{ml}^{-1}$ in buffer) ( $i$ and iii: brightfield and $i i$ and $i v$ : UV epifluorescence). E, Expression of $N b C a l S$ genes in tobacco leaf tissue infiltrated with buffer $\left(2.5 \mathrm{mM} \mathrm{MgCl}_{2}\right.$ and $1 \mathrm{mM} \mathrm{CaCl}$ ), LPS alone, or LPS and cPTIO (100 mM). Transcript data (C and E) were normalized against expression of elongation factor $1-\alpha(N b E F 1 \alpha)$ and calibrated against expression in untreated control samples. Treatment means (A and C) followed by different letters are significantly different based on Tukey's HSD test $(P \leq 0.05)$. Asterisks $(\mathrm{E})$ indicate significant differences between the treatment means (Student's $t$ test, $P \leq 0.05$ ). Data presented are the means \pm standard error for three independent experiments with four replicates. 
A role of $\mathrm{BCP}$ peroxiredoxin in attenuating LPS-mediated defense signaling was further corroborated in ' $\mathrm{Ca}$. L. asiaticus'infected grapefruit (Citrus $\times$ paradisi) leaves. Much higher (10-fold) BCP peroxiredoxin expression levels (Fig. 6B) were observed in grapefruit leaves with high ' $\mathrm{Ca}$. L. asiaticus' titer (cycle threshold $[\mathrm{Ct}]<31$ ) than in uninfected grapefruit leaves. Similar to the data presented in Figure 6A using tobacco

A

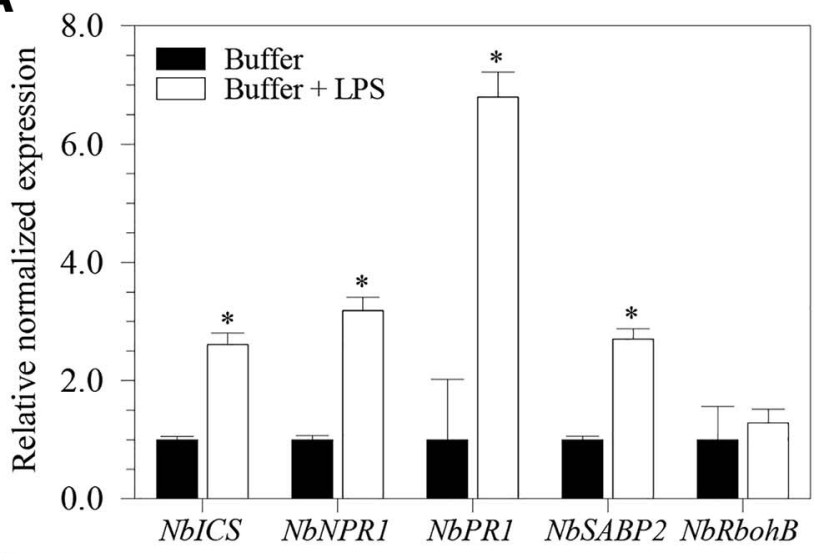

B

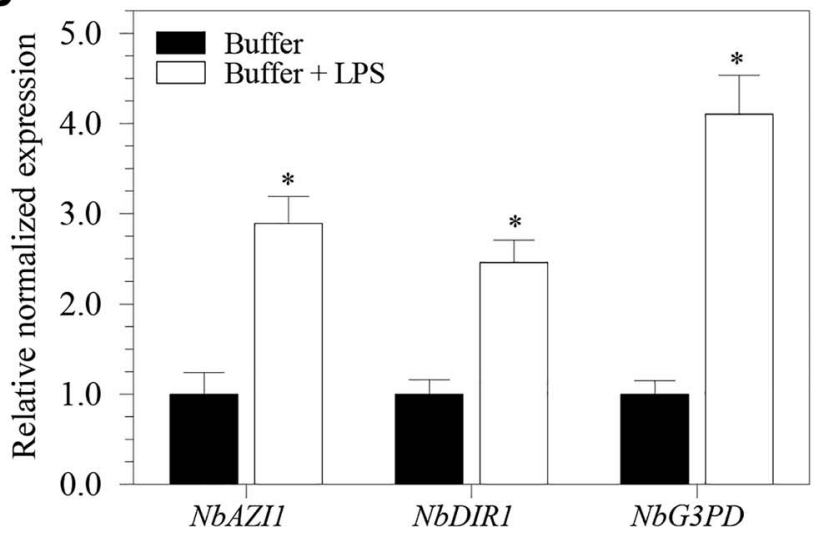

C

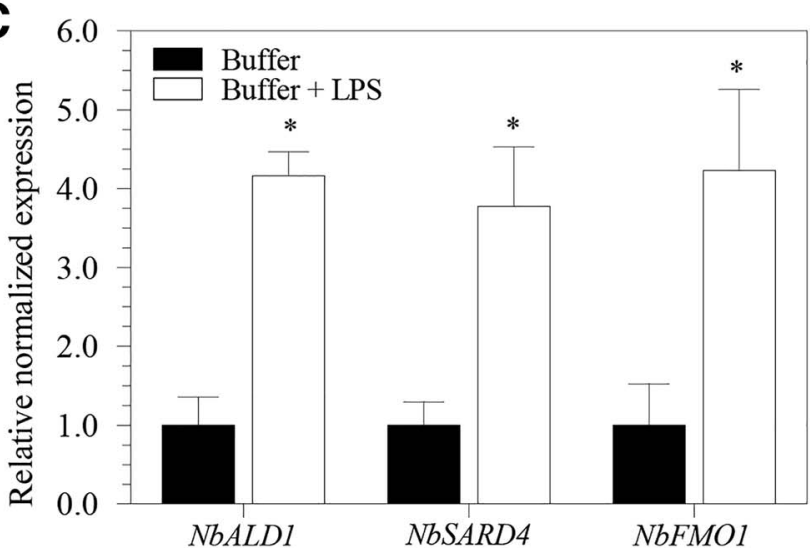

Fig. 5. Transcriptional activation of systemic acquired resistance signaling and priming genes in Nicotiana benthamiana suspension cultured cells treated with Liberibacter crescens lipopolysaccharides. Transcript data for A, salicylic acid (SA) biosynthesis (NbICS1) and SA signaling (NbNPR1, $N b S A B P 2$, and $N b P R-1)$; B, azelaic acid (AzA) signaling (NbAZI1, NbDIR1, and $N b G 3 P D$ ); and $\mathbf{C}$, pipecolic acid/N-hydroxypipecolic acid biosynthesis (NbALD1, NbSARD4, and NbFMO1) genes were normalized against expression of elongation factor 1- $\alpha(N b E F 1 \alpha)$ and calibrated against expression of each gene in untreated control samples. Data presented are the means \pm standard error for three independent experiments with four replicates. Asterisks indicate significant differences between the treatment means (Student's $t$ test, $P \leq 0.05)$. transiently expressing Lasbcp, lower levels of expression of AzA-signaling genes (CitAZI1, CitDIR1, and CitG3PD) were observed in ' $\mathrm{C} a$. L. asiaticus'-infected grapefruit in comparison with uninfected grapefruit leaves (Fig. 6C). Conversely, the expression of SA-signaling genes (CitPR-1, CitNPR1, and CitICS) was higher in infected grapefruit leaves than in uninfected leaves (Fig. 6C). Expression of two housekeeping genes (encoding glyceraldehyde-3-phosphate dehydrogenase, Cit$G A P D H$, and the SAND domain-containing protein CitSAND) was unaffected by ' $\mathrm{Ca}$. L. asiaticus' infection (Fig. 6C).

\section{'Ca. L. asiaticus'-secreted peroxiredoxin is a scavenger} of peroxynitrite radicals.

Weakly oxidative NO interacts with superoxide $\left(\mathrm{O}_{2}{ }^{-}\right)$, generating highly reactive and cytotoxic peroxynitrite $\left(\mathrm{ONOO}^{-}\right)$radicals under physiological conditions. Peroxynitrite reductase activity of ' $\mathrm{Ca}$. L. asiaticus' BCP peroxiredoxin was investigated because bacterial BCP peroxiredoxins have been shown to exhibit substrate specificity for peroxynitrite in addition to $\mathrm{H}_{2} \mathrm{O}_{2}$ and lipid peroxides (Horta et al. 2010; Reeves et al. 2011).

3-(4-Morpholinyl)sydnonimine hydrochloride (SIN-1) decays to spontaneously release both $\mathrm{NO}$ and $\mathrm{O}_{2}{ }^{-}$and, therefore, was used as a peroxynitrite donor. Agrobacterium-infiltrated tobacco leaf discs transiently expressing either GUS or ' $\mathrm{Ca}$. L. asiaticus' BCP peroxiredoxin ( $4 \mathrm{dpi}$ ) were excised and floated on halfstrength Murashige and Skoog (1/2 MS) medium containing $1 \mathrm{mM}$ SIN-1 for $6 \mathrm{~h}$. The presence of protein targets for tyrosine nitration was examined by immunoblot analysis using a commercial antibody cross-reactive against 3-nitrotyrosine $\left(\mathrm{NO}_{2}-\right.$ Tyr) (Fig. 7A). Western blot data revealed a highly abundant immunoreactive protein band (approximately $70 \mathrm{kDa}$ ) in the crude extract of tobacco leaf tissue exposed to SIN-1. However, this Tyr-nitrated band was greatly reduced in SIN-1-treated leaf tissue expressing ' $\mathrm{Ca}$. L. asiaticus' $\mathrm{BCP}$ peroxiredoxin, indicating quenching of peroxynitrite radicals by the $\mathrm{BCP}$ peroxiredoxin. The molecular identity of the Tyr-nitrated proteins observed in the immunoblot analysis is unknown.

Arabidopsis nitroproteome analyses had revealed two nitrated Tyr $\left(\mathrm{Y}^{*}\right)$ residues $\left(\mathrm{W}^{376} \mathrm{Y}^{*} \mathrm{DNEWGY} \mathrm{SQR}^{*} \mathrm{SQ}\right)$ in the chloroplast localized isoform of glyceraldehyde-3-phosphate dehydrogenase (GAPDH, EC 1.2.1.12) associated with loss in enzyme activity (Lozano-Juste et al. 2011). GAPDH enzymatic activity in tobacco leaves in response to SIN-1-induced nitrosative stress was therefore quantified (Fig. 7B) because the same two Tyr residues were also found to be contextually conserved in the tobacco GAPDH enzyme ( $\mathrm{W}^{378}$ YDNEWGYSQR). GAPDH enzymatic activity was not significantly different in SIN-1 untreated control leaves expressing either GUS or ' $\mathrm{Ca}$. L. asiaticus' BCP peroxiredoxin $\left(74.24 \pm 12.56\right.$ and $67.11 \pm 11.49 \mathrm{U} \mathrm{mg}^{-1}$ of protein, respectively). However, GAPDH activity was significantly reduced in GUS-expressing leaves after SIN-1 treatment $(24.95 \pm 9.02 \mathrm{U}$ $\mathrm{mg}^{-1}$ of protein). By comparison, the enzyme activity in the leaves treated with SIN-1 and expressing ' $\mathrm{Ca}$. L. asiaticus' peroxiredoxin $\left(60.87 \pm 13.97 \mathrm{U} \mathrm{mg}^{-1}\right.$ of protein) was similar to untreated controls expressing GUS. Taken together, the data in Figure 7 clearly indicated a role of ' $\mathrm{Ca}$. L. asiaticus' BCP peroxiredoxin in alleviating peroxynitrite-induced nitrosative stress by virtue of a peroxynitrite reductase activity.

\section{DISCUSSION}

Structural analysis revealed that $L$. crescens lipid A is pentaacylated with a VLCFA (26-OHC28:0) modification (Fig. 1A) (Black et al. 2021). The occurrence of up to four VLCFAs differing in their length and decoration have been reported in the free-living state of all wild-type Rhizobia except Azorhizobium caulinodans (Choma et al. 2017). The VLCFA-modified lipid A 
was found to be important but not crucial for $S$. meliloti chronic infection (Ferguson et al. 2005). Although causing impaired symbiosis, the lack of VLCFA-modified lipid A has largely been associated with compromised outer membrane permeability, resulting in increased sensitivity to low $\mathrm{pH}$, detergents, peptide antibiotics, osmotic pressure, and desiccation under in both in vivo and ex vivo environments (Choma et al. 2017). Repeated attempts to knock out lpxXL in $L$. crescens failed, strongly indicating that the role of VLCFA-modified LPS in L. crescens is primarily to enhance the barrier function of the outer membrane and may be necessary but not sufficient for its culturability.

Although the lipid A moiety alone is evidently sufficient for many of the biological effects of LPS, the lipid A attached to core oligosaccharide was the minimal structural requirement for LPS-mediated suppression of the HR in plants (Dow et al. 2000). S. meliloti LPS (27OHC28:0-modified) treatment induced and enhanced the yeast elicitor-mediated oxidative burst and alkalinization of the culture medium of nonhost tobacco cell cultures but suppressed these responses in host Medicago sativa (Albus et al. 2001). Absence of $l p x X L$ and acpXL in all strains of pathogenic ' $C a$. Liberibacter' spp. sequenced to date may imply a strong selective pressure against VLCFA-modified LPS in host phloem cells. Nonetheless, a role of VLCFAs in the elicitation of PTI responses has not been reported. LPS extracted from $S$. meliloti wild-type and acpXL mutant strains had similar sugar composition and exposed the same antigenic epitopes (Sharypova et al. 2003). Given that surface-exposed O-antigenic polysaccharide and the core oligosaccharide are conserved among all Liberibacter spp. (Thapa et al. 2020), significant differences in perception and subsequent immune responses to LPS from L. crescens or pathogenic 'Ca. L. asiaticus' (Fig. 1B) are not expected. In this regard, it is interesting to note that ' $\mathrm{Ca}$. $\mathrm{L}$. americanus' has lost almost all genes for LPS biosynthesis (Wulff et al. 2014), indicating strong selection pressure against LPS, presumably due to avoidance of PTI via the PAMP activity of lipid A.

The most widely studied effect of LPS on plant cells is its ability to suppress HR and PTI in both host and nonhost incompatible reactions regardless of the source of LPS (Erbs and Newman 2003). Although L. crescens LPS was used as a proxy in these experiments, the data presented in Figures 2 and 3 strongly indicate an important role of Liberibacter LPS in suppression of HR and NO-mediated elicitation of PTI in plants. Several lines of evidence indicate the immunogenic potential of ' $\mathrm{Ca}$. L. asiaticus' LPS in triggering a burst of arginine-derived NO and subsequent NO-mediated activation of SA signaling in citrus. Principle component analyses demonstrated a positive correlation between arginine levels and reduced symptoms (tolerance) in citrus cultivars infected with ' $C a$. L. asiaticus' (Killiny 2017). Likewise, accumulation of polyamines and enhanced transcript abundance of diamine oxidase $(C s D A O)$ and FAD-dependent polyamine oxidases $(C s P A O)$ may be associated with $\mathrm{NO}$ accrual in ' $\mathrm{Ca}$. L. asiaticus'-infected citrus leaves (Nehela and Killiny 2019). Oxidative catabolism of polyamines by DAO and PAO has been suggested to play a role in elevated NO generation (Wimalasekera et al. 2011). Polyamines have also been demonstrated to specifically reprogram NO-mediated signaling events via depressing tyrosine nitration and eliciting protein $S$ nitrosylation in salt-stressed citrus leaves (Tanou et al. 2014). ' $C a$. L. asiaticus'-infected citrus leaves displayed transcriptional upregulation of genes encoding the SA biosynthetic enzymes phenylalanine ammonia-lyase (CitPAL) and CitICS, as well as increased abundance of salicylate phytohormones (Nehela et al. 2018). Most importantly, all Liberibacter spp. sequenced to
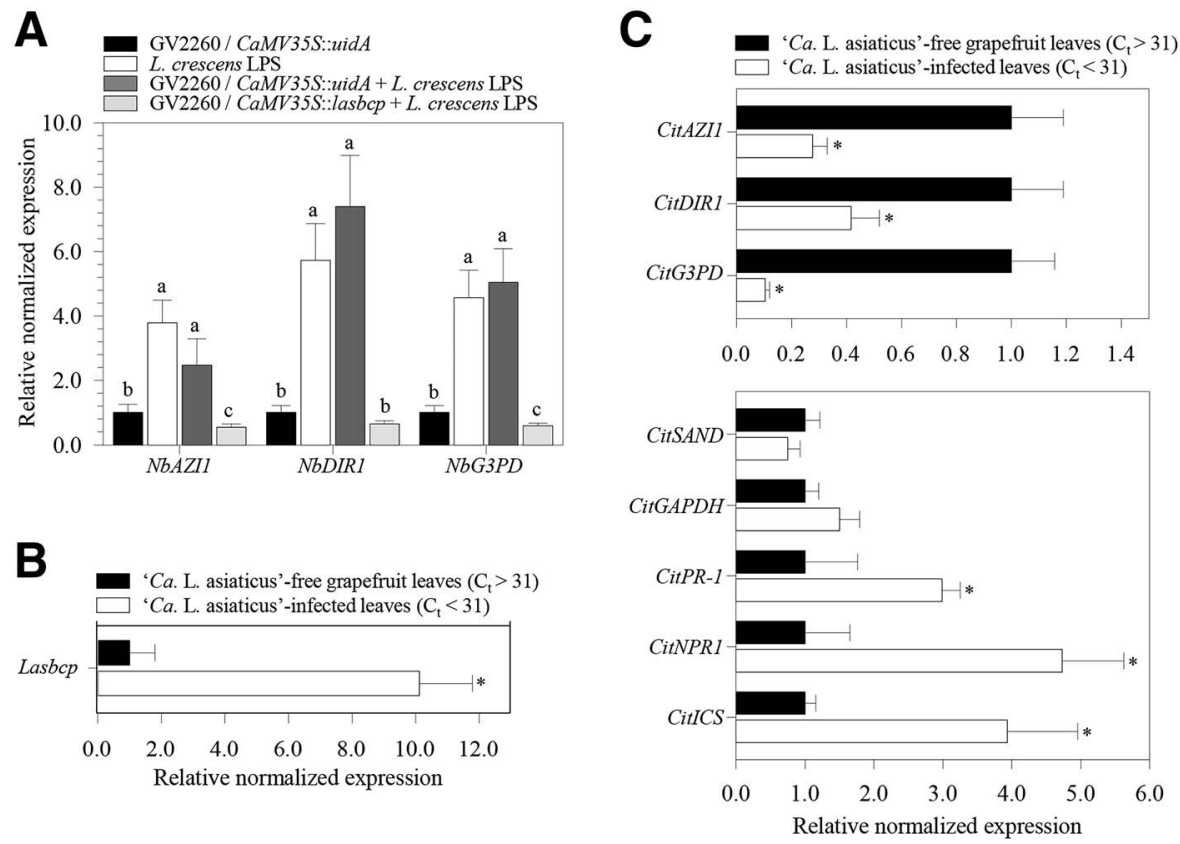

Fig. 6. 'Candidatus Liberibacter asiaticus' bacterioferritin comigratory protein (BCP) peroxiredoxin (Lasbcp) suppressed azelaic acid (AzA) signaling cascades in planta. A, Transient expression of Lasbcp in Nicotiana benthamiana leaves suppressed the L. crescens lipopolysaccharide (LPS)-induced AzA signaling cascade. Young, fully expanded tobacco leaves were infiltrated with Agrobacterium tumefaciens strain GV2260 carrying pCAMBIA2301 (CaMV35S::uidA) as a control or pAMB004 (CaMV35S::Lasbcp), with and without $L$. crescens LPS $\left(100 \mu \mathrm{g} \mathrm{ml}{ }^{-1}\right)$ infiltrated 4 days later. One leaf disc each from two individual leaves were excised $24 \mathrm{~h}$ after the LPS treatments and used for RNA extraction and quantitative real-time PCR analyses. B, Lasbcp expression in grapefruit (Citrus $\times$ paradisi) leaves with high (cycle threshold $[\mathrm{Ct}]<31)$ and low $(\mathrm{Ct}>31)$ levels of ' $\mathrm{Ca}$. L. asiaticus' infection. C, Transcriptional repression of AzA signaling (CitAZI1, CitDIR1, and CitG3PD) and activation of salicylic acid signaling (CitPR-1, CitNPR1 and CitICS $)$ genes in grapefruit leaves with high $(\mathrm{Ct}<31)$ and low $(\mathrm{Ct}>31)$ levels of ' $\mathrm{Ca}$. L. asiaticus' infection. Transcript data were normalized against expression of elongation factor 1- $\alpha(E F 1 \alpha)$. Data presented are the means \pm standard error for three independent experiments with four replicates. Means followed by different letters are significantly different based on Tukey's honestly significant difference test $(P \leq 0.05)$. 
date, including $L$. crescens, encode a functional SA hydroxylase gene $(\operatorname{sah} A)$ to degrade and suppress SA-mediated plant defenses (Li et al. 2017).

The short life span, radical nature, and ready permeability across lipid membranes is central to the LPS-triggered signaling function and multifaceted biological activity of NO. NO-mediated $S$-nitrosylation and nitration of target proteins influence redox signaling cascades as well as stress-related gene expression (Arasimowicz-Jelonek and Floryszak-Wieczorek 2019; Astier and Lindermayr 2012). S-nitrosylation of solvent-exposed cysteinyl thiol groups represents a fundamental and widespread posttranslational modification for the transduction of NO bioactivity.

A

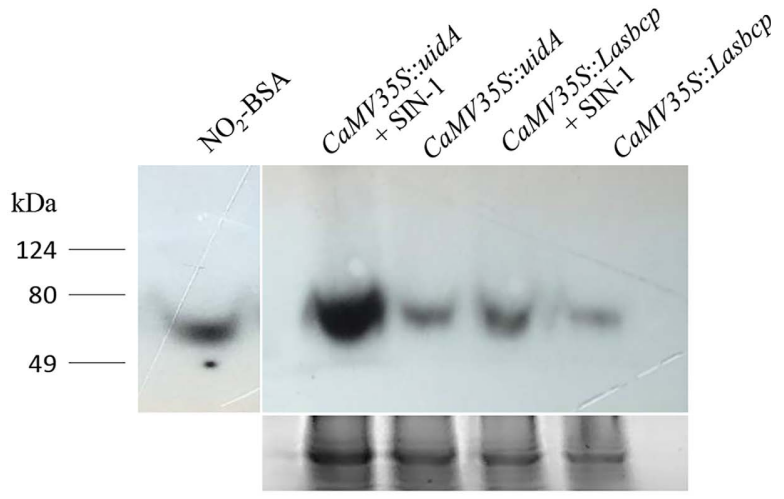

B

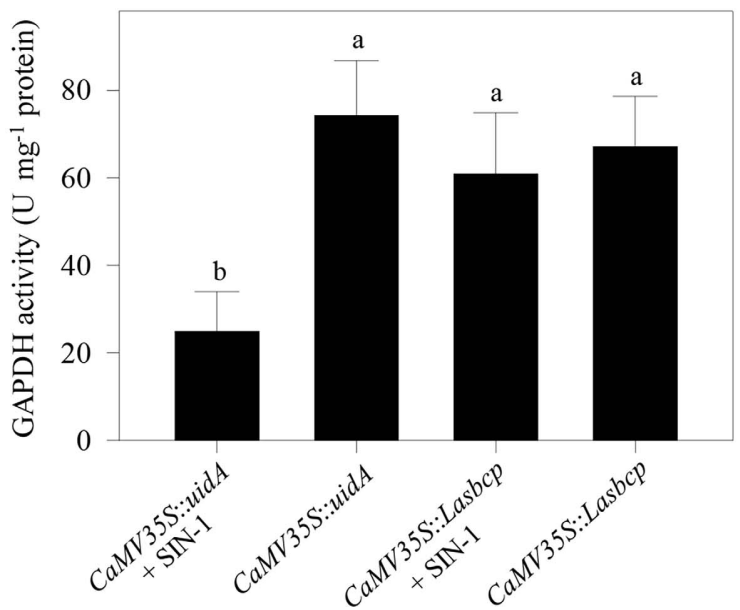

Fig. 7. Transient expression of 'Candidatus Liberibacter asiaticus' bacterioferritin comigratory protein (BCP) peroxiredoxin (Lasbcp) in Nicotiana benthamiana suppressed peroxynitrite-induced tyrosine-nitration of leaf proteins. A, Immunodetection of tyrosine-nitrated proteins extracted from leaves transiently expressing $\beta$-glucuronidase (GUS) (CaMV35S::uidA) and BCP peroxiredoxin (CaMV35S::Lasbcp) treated with 3-(4-morpholinyl)sydnonimine hydrochloride (SIN-1) $(1 \mathrm{mM})$. Crude protein extracts $(20 \mu \mathrm{g}$ per lane) were resolved by sodium dodecyl sulfate polyacrylamide gel electrophoresis ( 8 to $16 \%$ ), transferred to polyvinylidene fluoride membrane, and developed using rabbit polyclonal 3-nitrotyrosine $\left(\mathrm{NO}_{2}\right.$-Tyr) antibody (1:5000) and secondary antirabbit horseradish peroxidase immunoglobulin $\mathrm{G}$ conjugate $(1: 5000)$. Commercial nitrated bovine serum albumin $\left(\mathrm{NO}_{2}-\mathrm{BSA}\right)(1 \mu \mathrm{g})$ was used as positive control. Bottom panel shows Coomassie Brilliant Blue stained ribulose bisphosphate carboxylase-oxygenase (RuBisCO) as a control for protein loading. B, Glyceraldehyde-3-phosphate dehydrogenase (GAPDH) enzyme activity in tobacco leaves expressing GUS and BCP peroxiredoxin treated with SIN-1. One unit GAPDH activity is defined as the amount of enzyme required to yield $\mathrm{NADH}$ at $1 \mathrm{nmol} \mathrm{min}-1$ at $37^{\circ} \mathrm{C}$ under the assay conditions. Data presented are the means ( \pm standard error) for three independent experiments with three replicates. Treatment means followed by different letters are significantly different based on Tukey's honestly significant difference test $(P \leq 0.05)$.
NO-dependent elevated total GSH content, GSH/GSSG ratio, and transcriptional activity of $N b G S N O R$ (Fig. 4A to C) are consistent with the increased oxidative buffering capacity of LPS-treated tobacco cells and with GSH playing a key role in NO signaling. $S$-nitrosylation of GSH results in formation of GSNO (Astier et al. 2018), which is stable for several hours in aqueous solution. By contrast, NO has a very short (approximately 5 to $15 \mathrm{~s}$ ) half life in vivo (Floryszak-Wieczorek et al. 2006). GSNO functions as a ubiquitous NO donor reservoir via $S$-transnitrosylation of other cysteinyl thiols or release of NO by GSNOR activity (Astier et al. 2018; Mur et al. 2013). Pathogen-induced accumulation (Yun et al. 2011) and phloem-unloading and mobility of GSNO (Gaupels et al. 2017) temporally and spatially extend the signaling function of locally produced $\mathrm{NO}$ as a long-distance systemic molecule. GSNO-mediated cysteine $S$-nitrosylation reactions play an important role in HR regulation in Arabidopsis by suppressing ROS output of RBOH (Yun et al. 2011), DNA binding of HR regulator MYB30 (Tavares et al. 2014), and activity of cell death executioner metacaspase MC9 (Belenghi et al. 2007).

Callose deposition (Fig. 4D and E) and transcriptional upregulation of SA biosynthesis and signaling genes (Fig. 5A) in LPStreated tobacco cells mark the execution of an effective SAR response. SAR deployment is monitored through the enhanced expression of marker gene $P R-1$, requiring the recruitment of an $\mathrm{SA}$-dependent transcriptional enhanceosome to its promoter. NO plays a paradoxical and dose-dependent role in orchestrating SA perception and signaling via its precise effect on localization and activity of the transcriptional coactivator NPR1. Cysteine $S$-nitrosylation maintains cytosolic NPR1 in an oligomeric state. However, pathogen-triggered NO burst induces thioredoxincatalyzed reduction and subsequent nuclear translocation of cytosolic NPR1 monomers (Tada et al. 2008). In the nucleus, NPR1 interaction with the basic leucine zipper family of TGACG-BINDING (TGA) transcription factors TGA1 and TGA4 is required for binding of the enhanceosome complex to cognate promoter sequences (Sun et al. 2018; Tada et al. 2008). Both TGA1 and TGA4 are also subject to conformational modification by $S$-nitrosylation and $S$-glutathionylation (Lindermayr et al. 2010) and regulate SA biosynthesis from chorismate by transcriptional activation of the key SA-accumulating enzyme ICS1 (Sun et al. 2018). SA and MeSA accumulate in LPStreated cells and play a fundamental role in LPS-triggered SAR (Dow et al. 2000; Mhlongo et al. 2017). Successful SAR is further dependent upon phloem accumulation and unloading of MeSA, which is biologically inactive and only serves as a reservoir for SA. In distal tissues, MeSA is converted back to SA via MeSA esterase activity of SABP2 leading to SA-induced $P R-1$ gene expression (Forouhar et al. 2005).

Increased transcript abundance of SA signaling genes (Fig. $5 \mathrm{~A})$ was also accompanied by upregulation of AzA signaling (Fig. 5B) and NHP biosynthesis (Fig. 5C) genes in LPS-treated tobacco cells. AzA represents an essential and independent component for priming SAR (Jung et al. 2009; Yu et al. 2013). The lysine catabolite Pip and its derivative NHP are phloem-mobile chemical inducers of a light-dependent SAR defense, and their biosynthesis is coordinately regulated along with ICS1 (Vlot et al. 2021) and in response to LPS (Návarová et al. 2012).

Pathogen-induced NO and ROS both operate in distinct and additive feedback loops and contribute to the accumulation of AzA via peroxidative hydrolysis of oleic acid (18:1), linoleic acid (18:2), and linolenic acid (18:3) abundantly present in the plastid galactolipids monogalactosyldiacylglycerol (MGDG) and digalactosyldiacylglycerol (DGDG) (Gao et al. 2014). Peroxidative degradation of thylakoid lipids (Gao et al. 2014), LPSinduced oxidative burst (Shang-Guan et al. 2018), and NOS activity (Jasid et al. 2006) localized to plastids confirm a sentinel role for chloroplasts in plant immunity. AzA induces SAR by 
directly upregulating biosynthesis of phosphorylated sugar derivative G3P through G3P dehydrogenase (G3PD) activity. Symplastic mobility of G3P and AzA-mediated SAR requires a feedback regulatory loop between G3P, the LTP defective in induced resistance-1 (DIR1), and the LTP-like protein AzA insensitive-1 (AZI1) (Yu et al. 2013). Lipid profiling of Arabidopsis leaves undergoing HR revealed ROS-catalyzed galactolipid peroxidation responsible for the formation of AzA (Zoeller et al. 2012). Arabidopsis mutants defective in G3P biosynthesis were also deficient in AzA-mediated SAR (Yu et al. 2013). Accumulation of AzA primes plants to accumulate SA upon pathogen challenge and mutation of the AzA-inducible AZII gene results in the specific loss of SAR response triggered by pathogens (Jung et al. 2009).

Except for the presence of lpxXL in L. crescens, the LPS biosynthetic pathway is completely conserved between $L$. crescens and ' $\mathrm{Ca}$. L. asiaticus' (Supplementary Fig. S1; Fig. 1B). Although the evidence for bioactivity of ' $\mathrm{Ca}$. L. asiaticus' LPS is indirectly based on data confirming bioactivity of $L$. crescens LPS in tobacco, SAR elicitation in response to the LPS of pathogenic ' $C a$. Liberibacter' spp. likely occurs in planta. Potential SAR elicitation by endophytic bacteria (Fujiwara et al. 2018; Ha et al. 2019) present in citrus phloem cannot be discounted. Therefore, productive transmission of ' $\mathrm{Ca}$. L. asiaticus' by psyllids and systemic colonization of host phloem cells likely requires active molecular interference with LPS-mediated plant defense signaling. The substrate specificity of the secreted ' $\mathrm{Ca}$. L. asiaticus' $\mathrm{BCP}$ peroxiredoxin for organic peroxides (Jain et al. 2018, 2019b) probably dampens the LPS-triggered surge in peroxidative hydrolysis of plastid galactolipids MGDG and DGDG. The downregulation of AzA signaling genes in LPS-treated leaves by transiently expressed ' $\mathrm{Ca}$. L. asiaticus' BCP peroxiredoxin (Fig. 6A) confirms suppression of AzA-mediated SAR signaling. Based on the data presented in Figure 6, it is highly likely that Lasbcp attenuates LPS-mediated PTI in ' $C a$. L. asiaticus'-infected citrus host by dampening AzA signaling. Notably, expression of genes encoding G3PD (Kim et al. 2009) and G3P transporter (Albrecht and Bowman 2008) were downregulated in ' $\mathrm{Ca}$. L. asiaticus'-infected citrus leaves, indicating repression of AzA signaling.

' $C a$. L. asiaticus' BCP peroxiredoxin not only suppresses peroxidation of lipids but also scavenges peroxynitrite radicals (Fig. 7) that accumulate following an LPS-triggered ROS and NO burst. Extremely reactive peroxynitrite radicals are readily formed in a diffusion-limited reaction between $\mathrm{NO}$ and $\mathrm{O}_{2}{ }^{-}$and strongly exacerbate lipid peroxidation, antioxidant depletion, tyrosine nitration, and DNA damage (Arasimowicz-Jelonek and Floryszak-Wieczorek 2019). Nitration of solvent-accessible tyrosine residues to yield $\mathrm{NO}_{2}$-Tyr is a highly selective, lowabundance, and irreversible posttranslational modification that marks proteins for proteasome degradation (Castillo et al. 2015). Nitroproteome analyses of Arabidopsis, yeast, rabbit, and mouse revealed loss of GAPDH catalytic activity as a widespread molecular footprint for peroxynitrite-mediated tyrosine nitration (Lozano-Juste et al. 2011). A GAPDH activity assay in tobacco leaves treated with SIN-1 and transiently expressing 'Ca. L. asiaticus' BCP peroxiredoxin (Fig. 7B) confirmed mitigation of peroxynitrite-induced nitrosative stress by the bacterial $\mathrm{BCP}$ peroxiredoxin, corroborating the reduced presence of $\mathrm{NO}_{2}$-Tyr residues in an immunoblot assay (Fig. 7A). GSNOmediated $S$-nitrosylation is a key molecular switch regulating the intersecting ROS- and NO-mediated signaling cascades via reversible inhibition of the 2-Cys peroxiredoxin activity (Engelman et al. 2013). However, 1-Cys ' $C a$. L. asiaticus' BCP peroxiredoxin may not be susceptible to NO-mediated inhibition because in silico analysis (GPS-SNO 1.0) (Xue et al. 2010) did not predict $S$-nitrosylation modification sites in ' $\mathrm{Ca}$. L. asiaticus' BCP peroxiredoxin.
Rapid and systemic spread of ' $\mathrm{Ca}$. L. asiaticus' in citrus phloem is achieved through simultaneous (i) suppression of $\mathrm{RBOH}$-mediated localized and systemic immune responses, (ii) reducing accumulation of antimicrobial oxylipins, and (iii) dampening of SAR-associated defense response triggered by bacterial LPS. Suppression of AzA-mediated priming of SAR (Fig. 6) and mitigation of oxidative and cytotoxic peroxynitrite (Fig. 7) by ' $\mathrm{Ca}$. L. asiaticus' BCP peroxiredoxin is likely central to the biological role of antioxidative and tissue-protective properties ascribed to the LPS-induced NO burst in citrus phloem. The data presented in this report emphasize a crucial role of ' $C a$. L. asiaticus' BCP peroxiredoxin as a virulence factor, important in transmission of the bacterial pathogen to citrus (Jain et al. 2018, 2019b) but, more particularly, in explaining the very short latency period (measured in days) (Lee et al. 2015) and surprisingly long incubation period (measured in months) (Chiyaka et al. 2012). Two functionally distinct aspects of the complex activities of ' $\mathrm{Ca}$. L. asiaticus' $\mathrm{BCP}$ peroxiredoxin, likely involved in suppression of localized and systemic defense responses in citrus, are illustrated in Figure 8. One aspect involves its demonstrated substrate specificity for $\mathrm{H}_{2} \mathrm{O}_{2}$ and organic peroxides (Fig. 8A) (Jain et al. 2018, 2019b) and the other involves its substrate specificity for peroxynitrite radicals (Fig. 8B). Efficient scavenging of a wide array of cytotoxic peroxide and peroxynitrite radicals is essential for preserving the viability of both the host cell as well as the pathogen. We hypothesize that the secreted ' $\mathrm{Ca}$. L. asiaticus' $\mathrm{BCP}$ peroxiredoxin ensures (i) the viability of infected host phloem cells; (ii) successful colonization by ' $C a$. L. asiaticus'; (iii) repetitive cycles of psyllid acquisition and transmission; and (iv) rapid, systemic spread of the pathogen, all without triggering significant host defense responses and overt disease symptoms.

\section{MATERIALS AND METHODS}

\section{Tobacco cell suspension cultures.}

Tobacco ( $N$. benthamiana) callus cultures were established from leaf explants on MS medium (Murashige and Skoog 1962) containing 6-benzylaminopurine and 2,4-dichlorophenoxyacetic acid, each at $1 \mathrm{mg} \mathrm{ml}^{-1}$ (PhytoTechnology Laboratories); myoinositol at $100 \mathrm{mg} \mathrm{liter}{ }^{-1}$; sucrose at $20 \mathrm{~g} \mathrm{liter}^{-1}$; and $0.8 \%$ (wt/ vol) agar, $\mathrm{pH}$ 5.7. The suspension cultures were obtained by growing friable green calli on liquid medium (composition as above) with continuous shaking on a gyratory shaker at $150 \mathrm{rpm}$. All cultures were incubated under a 16-h photoperiod at 27 and $24^{\circ} \mathrm{C}$ (day and night, respectively) and florescent light at 130 to $150 \mu \mathrm{mol} \mathrm{m} \mathrm{m}^{-2} \mathrm{~s}^{-1}$ and subcultured every 14 days. All experiments were performed using cells in the early logarithmic growth phase 5 days after transfer to fresh medium.

\section{Extraction and purification of $L$. crescens LPS.}

Ten 1-liter cultures of $L$. crescens BT-1 were grown for 5 days in BM7A medium with gentle shaking at $150 \mathrm{rpm}$ at $28^{\circ} \mathrm{C}$ (Jain et al. 2019a). The cells were harvested at midlog phase (absorbance at $600 \mathrm{~nm}=0.6$ ) by centrifugation for $15 \mathrm{~min}$ at $5,000 \mathrm{rpm}$ and $4^{\circ} \mathrm{C}$. The bacterial pellets were resuspended and washed in prechilled, sterile water and centrifuged again. LPS was extracted using hot phenol and water. Basically, the pellets were lyophilized and resuspended in deionized water $\left(10 \mathrm{ml} \mathrm{g}^{-1}\right)$ and an equivalent amount of $90 \%$ phenol was added. The solutions were preheated to $68^{\circ} \mathrm{C}$, mixed and stirred for $20 \mathrm{~min}$ at $68^{\circ} \mathrm{C}$, then placed in an ice bath to cool. The chilled solutions were then centrifuged at $5,000 \times g$ for $20 \mathrm{~min}$, and the aqueous layer was collected. An equal volume of deionized water (at $68^{\circ} \mathrm{C}$ ) was added to the phenol fraction (heated to $68^{\circ} \mathrm{C}$ ), and the process was repeated twice. The three water layers were combined and dialyzed using a $10-\mathrm{kDa}$ 
dialysis membrane (Thermo Fisher Scientific, Waltham, MA, U.S.A.). The water-extracted, dialyzed, and lyophilized LPS was dissolved in $50 \mathrm{mM} \mathrm{MgCl}_{2}$ buffer, $\mathrm{pH} 7.5$ (LPS at $10 \mathrm{mg} \mathrm{ml}^{-1}$ ) and digested with RNAse A (3.5 $\left.\mathrm{U} \mathrm{ml}^{-1}\right)$ and DNAse I (3.5 $\left.\mathrm{U} \mathrm{ml}^{-1}\right)$
(Sigma-Aldrich, St. Louis, MO, U.S.A.) overnight at $37^{\circ} \mathrm{C}$ This was followed by proteinase $\mathrm{K}$ digestion (Sigma-Aldrich) $\left(20 \mathrm{U} \mathrm{ml}^{-1}\right)$. The LPS was then dialyzed as before and further purified by ultracentrifugation $(100,000 \times g, 16 \mathrm{~h})$ (Black et al. 2021).

A
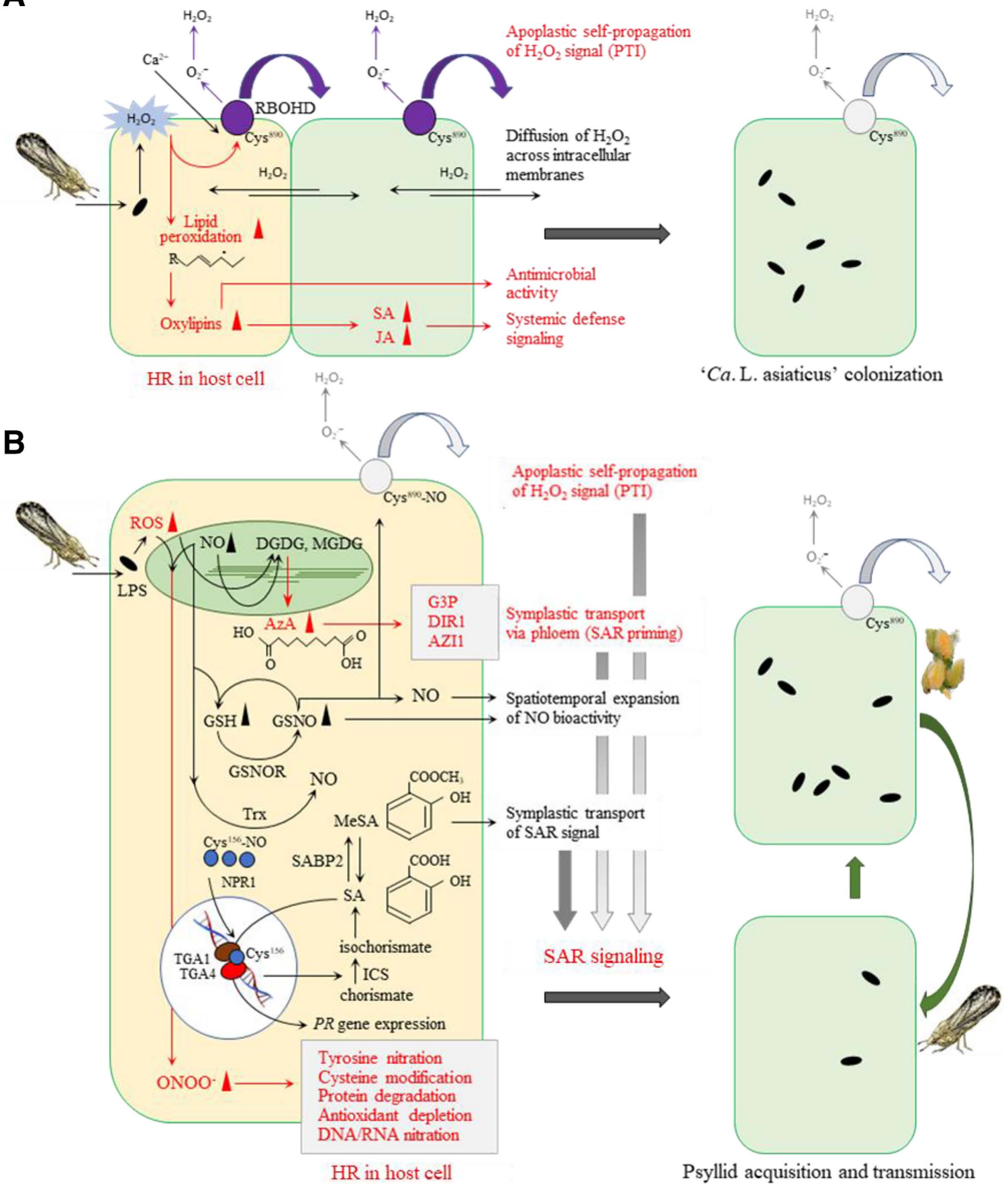

Fig. 8. Schematic representation of 'Candidatus Liberibacter asiaticus' bacterioferritin comigratory protein (BCP) peroxiredoxin-mediated suppression of multiple localized and long-distance defense responses focusing on $\mathbf{A}$, reactive oxygen species (ROS) and $\mathbf{B}$, nitric oxide (NO) signaling facilitating productive colonization of citrus phloem cells and repetitive cycles of bacterial acquisition and transmission by newly hatched nymphs and adult psyllids, respectively. ' $\mathrm{Ca}$. L. asiaticus' BCP peroxiredoxin alleviates A, respiratory burst oxidase homolog D (RBOHD)-mediated auto-propagating systemic $\mathrm{H}_{2} \mathrm{O}_{2}$ signal, lipid peroxidation, and subsequent oxylipin accumulation and $\mathbf{B}$, azelaic acid (AzA) accumulation and peroxynitrite-triggered nitrosative stress, leading to suppression of hypersensitive programmed cell death response in the host cell and dampening of AzA-mediated systemic acquired resistance (SAR) priming in distal tissues. All defense processes suppressed by BCP peroxiredoxin activity are marked by red arrows and noted in red text. AZI1, AzA insensitive-1; DIR1, defective in induced resistance-1; G3P, glycerol-3-phosphate; GSH, glutathione; GSNO, S-nitrosylglutathione; GSNOR, $S$-nitrosylglutathione reductase; ICS, isochorismate synthase 1; JA, jasmonic acid; LPS, lipopolysaccharide; MeSA, methyl salicylate; MGDG and DGDG, mono- and digalactosyldiacylglycerol; NPR1, NON-EXPRESSOR of PATHOGENESIS-RELATED GENES 1; PR, PATHOGENESISRELATED; PTI, pathogen-triggered immunity; SA, salicylic acid; SABP2, SA-binding protein 2; TGA 1 and 4, TGACG-BINDING transcription factors; and Trx, cytosolic thioredoxin. 
Purified LPS was dissolved at $1 \mathrm{mg} \mathrm{ml}^{-1}$ in water containing 2.5 $\mathrm{mM} \mathrm{MgCl} 2$ and $1 \mathrm{mM} \mathrm{CaCl}_{2}$ and shaken for $3 \mathrm{~h}$ on a rotary shaker $(300 \mathrm{rpm})$ at room temperature. The working LPS concentration for all experiments was $100 \mu \mathrm{g} \mathrm{ml}^{-1}$.

\section{$X$. perforans pathogenicity and growth assay in tobacco.}

The HR elicited by artificial inoculations of wild-type $X$. perforans strain GEV-485 and growth kinetics in nonhost tobacco were performed exactly as described by Schwartz et al. (2015). Briefly, $X$. perforans strain GEV-485 was grown in nutrient broth (Difco Laboratories, Detroit, MI, U.S.A.) for $24 \mathrm{~h}$ at $28^{\circ} \mathrm{C}$, harvested by centrifugation, rinsed once, and resuspended in sterile tap water to a final optical density at $600 \mathrm{~nm}$ $\left(\mathrm{OD}_{600 \mathrm{~nm}}\right)$ of $0.3\left(=5 \times 10^{8} \mathrm{CFU} \mathrm{ml} \mathrm{m}^{-1}\right)$. Fully expanded tobacco leaves were preinfiltrated with buffer alone $\left(2.5 \mathrm{mM} \mathrm{MgCl}_{2}\right.$ and $\left.1 \mathrm{mM} \mathrm{CaCl}_{2}\right)$ or buffer containing LPS $\left(100 \mu \mathrm{g} \mathrm{ml}^{-1}\right.$ in $2.5 \mathrm{mM}$ $\mathrm{MgCl}_{2}$ and $1 \mathrm{mM} \mathrm{CaCl}_{2}$ ) for $12 \mathrm{~h}$ before the bacterial inoculation. To observe a confluent HR, fully expanded tobacco leaves were infiltrated at $10^{8} \mathrm{CFU} \mathrm{ml} \mathrm{m}^{-1}$ using a $0.5-\mathrm{ml}$ needleless syringe, and the HR was visually apparent $1 \mathrm{dpi}$. For in planta population growth assays, leaves were syringe infiltrated with

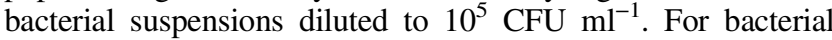
population measurements, two circular leaf discs were excised from the inoculated leaf tissue and macerated in $1 \mathrm{ml}$ of sterile water. In total, $50 \mu \mathrm{l}$ each of $10^{-1}$ dilutions $(0 \mathrm{dpi})$ and $10^{-3}$ and $10^{-4}$ dilutions ( 3 and $6 \mathrm{dpi}$ ) were plated on nutrient agar media and bacterial colonies were enumerated. The disease lesion phenotype was photographed at $6 \mathrm{dpi}$. All experiments were done in triplicate with two plants.

\section{$X$. citri subsp. citri pathogenicity and growth assay in sweet orange.}

$X$. citri subsp. citri strain 3213 was cultured on nutrient agar (Difco Laboratories) plates for 2 days at $28^{\circ} \mathrm{C}$. The bacteria were resuspended in sterile tap water $\left(10^{6} \mathrm{CFU} \mathrm{ml}{ }^{-1}\right)$ and pressure infiltrated into sweet orange leaves with the blunt end of a needleless syringe. To evaluate the growth of strain 3213 in the intercellular spaces of the plants, leaf discs from inoculated leaves were excised and ground in $1 \mathrm{ml}$ of sterile tap water. The samples were serially diluted and were plated on nutrient agar plates. The bacterial colonies were counted following incubation at $28^{\circ} \mathrm{C}$ for 3 days. All experiments were done in triplicate with two plants.

\section{Fluorimetric and enzymatic quantification of NO.}

To monitor the NO accumulation in LPS-treated tobacco cells, the DAF-FM DA fluorescence was measured using a multiplate reader with fluorescein isothiocyanate excitation and emission filters (BioTek Synergy HTX; BioTek, Winooski, VT, U.S.A.). Fluorescence intensity was measured every minute for $30 \mathrm{~min}$. The plate was rocked before measuring for $20 \mathrm{~s}$. NOS inhibitors L-NNA and L-NAME, and NO scavenger cPTIO were obtained from Sigma-Aldrich. Frozen cells $(1 \mathrm{~g})$ and $50 \mathrm{mg}$ of polyvinylpolypyrrolidone (PVPP) were pulverized under liquid nitrogen and resuspended in $2 \mathrm{ml}$ of prechilled NOS extraction buffer containing $50 \mathrm{~mm}$ Tris- $\mathrm{HCl}$ ( $\mathrm{pH} \mathrm{7.4),} 1 \mathrm{mM} \mathrm{Na}$-EDTA, $320 \mathrm{mM}$ sucrose, $1 \mathrm{mM}$ dithiothreitol (DTT), $1 \mathrm{mM}$ phenylmethylsulfonyl fluoride (PMSF), and 1\% (vol/vol) protease inhibitor cocktail (P9599; Sigma-Aldrich). The resulting protein extract was cleared by centrifugation at $12,000 \times g$ for $15 \mathrm{~min}$ at $4{ }^{\circ} \mathrm{C}$. The Nitric Oxide Synthase Activity Assay Kit (Abcam, Cambridge, United Kingdom) was used to quantify NOS activity by following the accumulation of a chromophore $\left(\mathrm{OD}_{540 \mathrm{~nm}}\right)$ due to oxidation of NO to nitrite in the presence of Griess Reagent. One unit of NOS activity is defined as the amount of enzyme required to yield $\mathrm{NO}$ at $1 \mu \mathrm{mol} \mathrm{min} \mathrm{m}^{-1}$ at $37^{\circ} \mathrm{C}$ under the assay conditions. Protein concentration was determined using the Bradford assay (Bio-Rad, Hercules, CA, U.S.A.) using bovine serum albumin as a standard.

\section{Quantification of GSH content.}

GSH levels were quantified according to the 5,5'-dithiobis2-nitrobenzoic acid (DTNB) enzymatic recycling method. Cells $(1 \mathrm{~g})$ were homogenized in $2 \mathrm{ml}$ of prechilled extraction buffer containing $6 \%$ metaphosphoric acid, $1 \mathrm{M} \mathrm{Na}_{4}$-EDTA, $1 \mathrm{mM}$ PMSF, and $50 \mathrm{mg}$ PVPP, followed by centrifugation at 12,000 $\times g$ for $15 \mathrm{~min}$ at $4^{\circ} \mathrm{C}$. The supernatant was divided into two parts to measure total GSH and GSSG, respectively. The reaction was set in a cuvette in a volume of $100 \mu$ l containing $20 \mu \mathrm{l}$ of crude extract, $70 \mu \mathrm{l}$ of NADPH, and $10 \mu \mathrm{l}$ of DTNB. NADPH $\left(0.248 \mathrm{mg} \mathrm{ml}^{-1}\right)$ and DTNB $(6 \mathrm{mM})$ were both prepared in $143 \mathrm{mM}$ sodium (Na)-phosphate buffer ( $\mathrm{pH}$ 7.5) containing $6.3 \mathrm{mM} \mathrm{Na}$-EDTA. The mixtures were incubated at $30^{\circ} \mathrm{C}$ for $15 \mathrm{~min}$. The reaction was initiated by adding $10 \mu \mathrm{l}$ of GSSG reductase (EC 1.6.4.2) (G3664; Sigma-Aldrich) diluted to 266 units $\mathrm{ml}^{-1}$ in Na-phosphate-EDTA buffer (pH 7.5). One unit of GSSG reductase reduces oxidized GSH at $1.0 \mathrm{mM}$ $\min ^{-1}$ at $\mathrm{pH} 7.6$ and $25^{\circ} \mathrm{C}$. The rate of stoichiometric formation of 5-thio-2 nitrobenzoic acid (TNB) from DTNB was followed at $412 \mathrm{~nm}$, and GSH concentration was expressed as micromoles per milligram of protein. For the estimation of GSSG, 2-vinylpyridine was added to the supernatant to remove $\mathrm{GSH}$ for $1 \mathrm{~h}$ at $25^{\circ} \mathrm{C}$. GSH content was determined after subtracting GSSG from the total GSH.

\section{Callose deposition assay.}

Callose deposition in LPS-infiltrated leaves was detected with aniline blue staining (Jain et al. 2018). Briefly, the LPS-treated leaf tissue ( 2 dpi) was cleared and dehydrated in $100 \%$ ethanol. Cleared leaves were washed with distilled water and then stained overnight at room temperature in $0.01 \%$ aniline blue and $67 \mathrm{mM} \mathrm{K} \mathrm{HPO}_{4}(\mathrm{pH} \mathrm{12.0)}$. Stained material was mounted in $50 \%$ glycerol ( $\mathrm{vol} / \mathrm{vol}$ ) and observed under ultraviolet epifluorescence (LSM5 Pascal Confocal Laser-Scanning Microscope; Carl Zeiss Microscopy LLC, Thornwood, NY, U.S.A.).

\section{' $\mathrm{Ca}$. L. asiaticus' quantification in grapefruit leaves.}

Grapefruit leaf midrib tissue samples were collected from a commercial grove using 1.5-ml Eppendorf tubes, each containing four to five zirconium oxide beads $(2.0 \mathrm{~mm}$ in diameter) (Next Advance, Inc., Troy, NY, U.S.A.) forcibly closed over young but fully expanded leaves. Samples were placed under dry ice in the field, transported cold to the lab for processing, and held at $-80^{\circ} \mathrm{C}$ until processing. Leaves were ground dry using a Tissuelyser (Qiagen, Germantown, MD, U.S.A.) at high speed for $15 \mathrm{~s}$, then refrozen using liquid $\mathrm{N}_{2}$, and the grinding was repeated until the tissue was finely pulverized. Total DNA was extracted using the DNeasy Plant Mini kit (Qiagen). ' $C a$. L. asiaticus' titer was quantified using the 16S ribosomal DNA primers and FAM/Iowa Black FQ label probe set (IDT Inc., Coralville, IA, U.S.A.) described previously by $\mathrm{Li}$ et al. (2006). Values above $31 \mathrm{Ct}$ were considered negative for ' $\mathrm{Ca}$. L. asiaticus' infection.

RNA isolation and gene expression analyses by qRT-PCR.

Plant and insect material were pulverized under liquid nitrogen and total RNA was extracted by Trizol reagent (Invitrogen, Carlsbad, CA, U.S.A.) following the manufacturer's protocol. Total RNA was resuspended in nuclease-free water to $500 \mathrm{ng}$ $\mu \mathrm{l}^{-1}$ and cleaned with TURBO DNA-free (DNase) Kit (Ambion, Austin, TX, U.S.A.). First-strand cDNA was synthesized from $1 \mu \mathrm{g}$ of purified RNA template using the iScript Advanced cDNA Synthesis Kit (Bio-Rad) and diluted fivefold for qRTPCR analyses. In total, $20 \mu \mathrm{l}$ of qPCR consisted of $10 \mu \mathrm{l}$ of $2 \times$ QuantiNova SYBR Green PCR Mix (Qiagen), $1 \mu$ of each 
primer $(5 \mu \mathrm{m}), 2 \mu \mathrm{l}$ of diluted cDNA template, and $6 \mu \mathrm{l}$ of DNase/RNase free water. The thermal cycling protocol entailed an initial activation step at $95^{\circ} \mathrm{C}$ for $2 \mathrm{~min}$, followed by 40 cycles of $95^{\circ} \mathrm{C}$ for $5 \mathrm{~s}$ and $60^{\circ} \mathrm{C}$ for $10 \mathrm{~s}$. All cDNA samples were run in triplicate using a CFX96 Touch Real-Time PCR detection system (Bio-Rad). Optical data were acquired during the annealing step and the fidelity of PCR was monitored by melting-curve analysis beginning at 55 through $95^{\circ} \mathrm{C}$, ramped at $0.1^{\circ} \mathrm{C} \mathrm{s}^{-1}$. The gene-specific primers are listed in Table 1 . Transcript abundance data for tobacco were normalized against expression of elongation factor $1-\alpha(E F 1-\alpha)$ following the $2^{-\Delta \Delta \mathrm{Ct}}$ method for relative quantification. Expression of ' $C a$. L. asiaticus' genes was normalized against that of DNA topoisomerase (ATP-hydrolyzing) subunit B $(g y r B)$. Data were analyzed using SAS for Windows (version 9.2; SAS Institute Inc, Cary, NC, U.S.A.) and Student's $t$ tests were performed to separate treatment means. A probability of $5 \%$ was used to determine statistically significant differences.

\section{Agrobacterium-mediated transient expression assays in tobacco.}

Agrobacterium tumefaciens strain GV2260 cells containing binary vectors pCAMBIA2301 (CaMV35S::uidA) and pAMB004 (CaMV35S::Lasbcp) (Jain et al. 2018) were cultured overnight in Luria-Bertani broth (Sigma-Aldrich) with rifampicin at $50 \mu \mathrm{g}$ $\mathrm{ml}^{-1}$ and kanamycin at $50 \mu \mathrm{g} \mathrm{ml} \mathrm{g}^{-1}$ at $28^{\circ} \mathrm{C}$. The bacteria were harvested and resuspended in Agrobacterium-induction medium containing $10 \mathrm{~mm} \mathrm{MgCl}, 10 \mathrm{~mm}$ morpholineethanesulfonic acid (pH 5.6), and $200 \mu \mathrm{M}$ acetosyringone followed by incubation for $4 \mathrm{~h}$ with shaking at $25^{\circ} \mathrm{C}$. The cultures were diluted to $\mathrm{OD}_{600 \mathrm{~nm}}=$ 0.2 . Three fully expanded young tobacco leaves were syringe infiltrated and the infiltrated leaf tissues were sampled for qRTPCR and Western blot analyses.

\section{Electrophoretic methods and Western blot analysis.}

Approximately $500 \mathrm{mg}$ of leaf tissue was pulverized under liquid nitrogen and resuspended in $1 \mathrm{ml}$ of extraction buffer

Table 1. Primers used in this study

\begin{tabular}{|c|c|c|c|}
\hline Gene $^{a}$ & Forward primer sequence $\left(5^{\prime} \rightarrow 3^{\prime}\right)$ & Reverse primer sequence $\left(5^{\prime} \rightarrow 3^{\prime}\right)$ & Accession number \\
\hline$N b A L D 1$ & AGACTCGAGCCCTAAGTCTATC & CCTGTGAATCCAGCCATCTT & Niben101Scf04547g02001 \\
\hline$N b A Z I 1$ & СССТСТTТСТСТАAGССТTСТTC & CGGCTTTGGCTTTGGTTTAG & Niben101Scf27717g00001 \\
\hline NbCalS1 & TCAGCTCTTTGGCACTCTTAAT & AGGAATCTGCTATGGATGTGC & Niben $101 \mathrm{Ctg} 12655 \mathrm{~g} 00004$ \\
\hline $\mathrm{NbCalS5}$ & AGGGTGATGATGCTCTCAAAG & TTCCAGCCCAATCTCCATAAC & Niben101Scf09955g01007 \\
\hline NbCalS9 & GAGGCTCTGAAGGTGAGAAATC & CCAGTAAACACATGCTCCCTAA & Niben101Scf11608g01009 \\
\hline NbCalS10 & CTCCGACTTCCCACTATTCTTG & CTGGTTTCCTGGTTGGACATA & Niben101Scf01826g07010 \\
\hline NbCalS12 & TCTGCGAATGCGACAATGA & GATGGTCAGCTAAGAGGTTATG & Niben101Scf01023g07010 \\
\hline NbDIRl & CAGCGTGTAAGCCATCAGTAA & AAGAACACAAGCACTGCAAATC & Niben101Scf10524g04002 \\
\hline$N b E F 1 \propto$ & GACCACTGAAGTTGGATCTGTTG & TAGCACCAGTTGGGTCCTTCTT & Niben101Scf04639g06007 \\
\hline$N b F M O 1$ & AGTGGTATGCGTTCGAGTATTT & CCTTGAACACTTCTGGTCCTT & Niben101Scf05682g00009 \\
\hline$N b G 3 P D$ & GAAACGCGAGAAGTGTTTATGG & GGATCTAGTTCAGCCTCAATACC & Niben101Scf01634g06003 \\
\hline$N b G S N O R$ & CCAAAGAGCATGAGAAACCAATAC & ACTCTAAAGCAGCCCTCATAAC & Niben101Scf03263g08013 \\
\hline NbICS & CTGGATGTAGAAATGGTGAGGAG & GAGGCAGTCCCGATGAAATAG & Niben101Scf00593g04010 \\
\hline$N b N P R 1$ & CAGCTATGAGGAAAGAGCCTAAA & CCATCGGAAGTCAGATCAGAAG & Niben101Scf14780g01001 \\
\hline$N b P R-1$ & TGTAGGCGTAGAACCTTTAACC & CGCCGTATTGACCATGAGAA & Niben101Scf00107g03008 \\
\hline$N b R b o h B$ & TTTCTCTGAGGTTTGCCAGCCACCA & CTTCATGTTGTTGACAATGTCTTT & Niben101Scf07345g00016 \\
\hline$N b S A B P 2$ & GCCGAGAGTTGGTTGGATAC & CATAGCTGGTAGAGCTTGTGAG & Niben101Scf00034g00012 \\
\hline NbSARD4 & GAACTCACTGTCTACCGAACTG & AGTACCAGCACCAATCATCAA & Niben101Scf09840g00001 \\
\hline CitAZII & CCATCAAAGCGAACATTTTGG & CGTTCAAAAGAAGGCTGAGTGA & Cg5g008450 \\
\hline CitDIR1 & GCAATGCTTGTGTGGTTACAA & AATAGGAGGGTTGCACTTGG & orange1.1t01576.1 \\
\hline CitEF $1 \alpha$ & TTGAGAAGGAGCCCAAGTTC & GTGGGTAGTCAGAGAAGGTTTC & Cs8g17000.1 \\
\hline CitG3PD & GCTGTGTGGGATGCTGATATT & CTGGCACCGTAATTCTCTCTTT & Cs7g02400.1 \\
\hline CitGAPDH & ACTCCAGAGGGATGATGTGG & ATGGGATCTCCTCTGGGTTC & Cs2g14940.1 \\
\hline CitGSNOR & GCTGGAGCTTCACGTGTTAT & TGTCATGGTCCTTGGGATTTAC & Cs5g28880.1 \\
\hline CitICS & CCTGATGCTCCAGCCTTTAT & AAGCAGTTGTTCCACCTCTAC & Cs5g04210.1 \\
\hline CitNPR1 & ATAGACTTGCGTGTGGAACTC & TCTGAGTCTAGTGCTCGATGTA & Cs4g14600.1 \\
\hline CitPR-1 & GAGTGTTGGCTGTGGTAGAG & TGCATGGGAAGAGAGAATTAGG & Cs8g03430.1 \\
\hline CitSAND & GCATCAGCTGCACAGAAGAG & GGAATGTAGCTGGGTTCCAA & Cs8g16530.1 \\
\hline LaslpxA & CAGGGCATGTCATTGTTGATG & ACCCGTCATCCCTCCTATAA & CLIBASIA_RS02185 \\
\hline LaslpxB & GTGCGTTGGATTGAAAGGTTATC & GACCTGCTGGCTTCTTTGTA & CLIBASIA_RS02195 \\
\hline LaslpxC & GTTCCTATCATGGACGGAAGTG & TAACGACGCTTGGCTGTTAG & CLIBASIA_RS05250 \\
\hline LaslpxD & GAAGGAGGTATTAGTCCGCAAG & CTCAACGCCCGGATATACAA & CLIBASIA_RS02175 \\
\hline LaslpxI & ACGGGATATATTGGCTGCTATG & CGGTTCCTTCAATCCCTTCTAA & CLIBASIA_RS02190 \\
\hline LaslpxK & CATGCTCCCATTCCTGTTATTTG & CGACCATATCCACGCGATAAA & CLIBASIA_RS01385 \\
\hline LaskdtA & GCTTGGGTGTGCTATTCTATCT & CGGCTAATGTCCCAACTTCT & CLIBASIA_RS01390 \\
\hline LasgyrB & TTGAACAAGCTGTAATTTCTGG & ATCTGTTTGCCAATTTAGAAGC & CLIBASIA_RS01960 \\
\hline LasprfA & TGTCTGAATCGCCTTCTGTC & GATCACCGATGACAGTATGC & CLIBASIA_RS03810 \\
\hline Lasbcp & GTCAACTATCCTTATCGGCATCTC & CTCATCGGCAAGCAGTGTAATA & CLIBASIA_RS00445 \\
\hline LasflgF & GAGATGCTTGGTTTGCATTGG & ATTTCCCACTTGCCGATACC & CLIBASIA_RS02610 \\
\hline
\end{tabular}

${ }^{\mathrm{a}} \mathrm{Nb}=$ Nicotiana benthamiana genome project; Cit = Citrus genome project; Las = 'Candidatus Liberibacter asiaticus' psy62 (GenBank accession number NC012985.3), ALD1 = AGD2-LIKE DEFENSE RESPONSE PROTEIN-1; AZI1 = Azelaic acid insensitive-1; CalS = callose synthase; DIR1 = DEFECTIVE IN INDUCED RESISTANCE-1; EF1 $\alpha=$ elongation factor $1-\alpha ;$ FMO1 = FLAVIN-DEPENDENT MONOOXYGENASE-1; G3PD = glycerol-3-phosphate dehydrogenase; $G A P D H=$ glyceraldehyde-3-phosphate dehydrogenase; GSNOR = $S$-nitrosylglutathione reductase; ICS = isochorismate synthase $1 ;$ NPR1 = NON-EXPRESSOR of PATHOGENESIS-RELATED GENES 1; PR-1 = PATHOGENESIS-RELATED 1; $R b o h B=$ respiratory burst oxidase homolog $\mathrm{B} ; S A B P 2=$ salicylic acid-binding protein $2 ; S A R D 4=S A R-D E F I C I E N T 4 ;$ SAND family protein $=$ vacuolar fusion protein MON1 homolog $\mathrm{B} ; \operatorname{lp} x A=\mathrm{UDP}-\mathrm{N}$-acetylglucosamine acyltransferase, EC:2.3.1.129; $l p x B=1$ lipid-A-disaccharide synthase, EC:2.4.1.182; $\quad l p x C=$ UDP-3-O-[3-hydroxymyristoyl] N-acetylglucosamine deacetylase, EC:3.5.1.108; lpxD = UDP-3-O-(3-hydroxymyristoyl) glucosamine N-acyltransferase, EC:2.3.1.191; lpxI = UDP-2,3-diacylglucosamine hydrolase, EC:3.6.1.54; lpxK = tetraacyldisaccharide $4^{\prime}$-kinase, $\mathrm{EC}: 2.7 .1 .130 ; k d t A=3$-deoxy-D-manno-octulosonic acid transferase, EC:2.4.99.12; gyrB = DNA topoisomerase $(\mathrm{ATP}$-hydrolyzing $)$ subunit $\mathrm{B}$; prfA = peptide chain release factor 1 ; lasbcp = bacterioferritin scomigratory protein peroxiredoxin; and flg $F=$ flagellar basal-body rod protein gene 
containing $50 \mathrm{mM}$ sodium phosphate ( $\mathrm{pH} 7.0$ ), $150 \mathrm{mM} \mathrm{NaCl}$, $1 \mathrm{mM} \mathrm{Na}$-EDTA, $50 \mathrm{mg}$ PVPP, $1 \mathrm{mM}$ DTT, $1 \mathrm{mM}$ PMSF, and $1 \%(\mathrm{vol} / \mathrm{vol})$ protease inhibitor cocktail. The crude extract was cleared by centrifugation at $12,000 \times g$ for $15 \mathrm{~min}$ at $4^{\circ} \mathrm{C}$. The soluble protein concentration was determined using the Bradford assay (Bio-Rad). Protein extracts were boiled for $5 \mathrm{~min}$ in $2 \times$ Laemmli loading buffer (Bio-Rad) and separated by 8 to $16 \%$ Mini-PROTEAN TGX Precast Gels (Bio-Rad). The proteins were transferred to polyvinylidene fluoride membranes (Immobilon P; Millipore Corp., Bedford, MA, U.S.A.) using a Semi-Dry Transfer System (Bio-Rad). For immunodetection, a rabbit polyclonal antibody against $\mathrm{NO}_{2}$-Tyr (Abcam) and secondary antirabbit immunoglobulin $\mathrm{G}$ were used at 1:5000 dilutions. The immunoreactive bands were detected with Clarity Western ECL Substrate (Bio-Rad).

\section{GAPDH activity assay.}

The enzymatic GAPDH activity was determined using a GAPDH Activity Assay Kit (Abcam) following the manufacturer's protocol. The assay is based on colorimetric measurement of NADH formation catalyzed by GAPDH. Leaf tissue was ground in liquid nitrogen, resuspended in the provided GAPDH assay buffer $\left(0.5 \mathrm{~g} \mathrm{ml}^{-1}\right)$, prechilled, and supplemented with $1 \mathrm{mM}$ DTT, $1 \mathrm{mM}$ PMSF, and $1 \%$ (vol/vol) protease inhibitor cocktail. The crude protein extract was cleared by centrifuging at $12,000 \times g$ for $15 \mathrm{~min}$ at $4^{\circ} \mathrm{C}$. The reactions were incubated with GAPDH substrates and the provided color developer at $37^{\circ} \mathrm{C}$. $\mathrm{NADH}$ production $\left(\mathrm{OD}_{450 \mathrm{~nm}}\right)$ was followed in kinetic mode for $10 \mathrm{~min}$ and quantified against a standard curve generated using 2.5 to $12.5 \mathrm{nmol} \mathrm{NADH}$ per reaction. One unit of GAPDH activity was calculated as the nanomoles of NADH produced per minute and was normalized to the protein content.

\section{ACKNOWLEDGMENTS}

We thank P. Rayside for excellent technical assistance.

\section{AUTHOR-RECOMMENDED INTERNET RESOURCES}

Citrus genome project: https://www.citrusgenomedb.org

GPS-SNO 1.0: http://sno.biocuckoo.org/

Nicotiana benthamiana genome project:

https://solgenomics.net/organism/Nicotiana_benthamiana/genome

\section{LITERATURE CITED}

Albrecht, U., and Bowman, K. D. 2008. Gene expression in Citrus sinensis (L.) Osbeck following infection with the bacterial pathogen Candidatus Liberibacter asiaticus causing huanglongbing in Florida. Plant Sci. 175:291-306

Albus, U., Baier, R., Holst, O., Pühler, A., and Niehaus, K. 2001. Suppression of an elicitor-induced oxidative burst reaction in Medicago sativa cell cultures by Sinorhizobium meliloti lipopolysaccharides. New Phytol. 151:597-606.

Arasimowicz-Jelonek, M., and Floryszak-Wieczorek, J. 2019. A physiological perspective on targets of nitration in NO-based signaling networks in plants. J. Exp. Bot. 70:4379-4389.

Astier, J., Gross, I., and Durner, J. 2018. Nitric oxide production in plants: An update. J. Exp. Bot. 69:3401-3411.

Astier, J., and Lindermayr, C. 2012. Nitric oxide-dependent posttranslational modification in plants: An update. Int. J. Mol. Sci. 13:15193-15208.

Belenghi, B., Romero-Puertas, M. C., Vercammen, D., Brackenier, A., Inzé, D., Delledonne, M., and Van Breusegem, F. 2007. Metacaspase activity of Arabidopsis thaliana is regulated by S-nitrosylation of a critical cysteine residue. J. Biol. Chem. 282:1352-1358.

Black, I. M., Heiss, C., Jain, M., Muszyński, A., Carlson, R. W., Gabriel, D. W., and Azadi, P. 2021. Structure of lipopolysaccharide from Liberibacter crescens is low molecular weight and offers insight into Candidatus Liberibacter biology. Int. J. Mol. Sci. 22:11240.

Castillo, M. C., Lozano-Juste, J., González-Guzmán, M., Rodriguez, L. Rodriguez, P. L., and León, J. 2015. Inactivation of PYR/PYL/RCAR
ABA receptors by tyrosine nitration may enable rapid inhibition of ABA signaling by nitric oxide in plants. Sci. Signal. 8:ra89.

Chiyaka, C., Singer, B. H., Halbert, S. E., Morris, J. G., Jr., and van Bruggen, A. H. 2012. Modeling huanglongbing transmission within a citrus tree. Proc. Natl. Acad. Sci. U.S.A. 109:12213-12218.

Choma, A., Komaniecka, I., and Zebracki, K. 2017. Structure, biosynthesis and function of unusual lipids $A$ from nodule-inducing and $\mathrm{N}_{2}$-fixing bacteria. Biochim. Biophys. Acta Mol. Cell Biol. Lipids 1862:196-209.

Clark, K., Franco, J. Y., Schwizer, S., Pang, Z., Hawara, E., Liebrand, T. W. H., Pagliaccia, D., Zeng, L., Gurung, F. B., Wang, P., Shi, J., Wang, Y., Ancona, V., van der Hoorn, R. A. L., Wang, N., Coaker, G., and Ma, W. 2018. An effector from the huanglongbing-associated pathogen targets citrus proteases. Nat. Commun. 9:1718.

Clark, K. J., Pang, Z., Trinh, J., Wang, N., and Ma, W. 2020. Sec-delivered effector 1 (SDE1) of 'Candidatus Liberibacter asiaticus' promotes citrus huanglongbing. Mol. Plant-Microbe Interact. 33:1394-1404.

Desaki, Y., Kouzai, Y., Ninomiya, Y., Iwase, R., Shimizu, Y., Seko, K., Molinaro, A., Minami, E., Shibuya, N., Kaku, H., and Nishizawa, Y. 2018. OsCERK1 plays a crucial role in the lipopolysaccharide-induced immune response of rice. New Phytol. 217:1042-1049.

Dong, X., Hong, Z., Chatterjee, J., Kim, S., and Verma, D. P. S. 2008. Expression of callose synthase genes and its connection with Npr1 signaling pathway during pathogen infection. Planta 229:87-98.

Dow, M., Newman, M. A., and von Roepenack, E. 2000. The induction and modulation of plant defense responses by bacterial lipopolysaccharides. Annu. Rev. Phytopathol. 38:241-261.

Engelman, R., Weisman-Shomer, P., Ziv, T., Xu, J., Arnér, E. S., and Benhar, M. 2013. Multilevel regulation of 2-Cys peroxiredoxin reaction cycle by $S$-nitrosylation. J. Biol. Chem. 288:11312-11324.

Erbs, G., and Newman, M. A. 2003. The role of lipopolysaccharides in induction of plant defence responses. Mol. Plant Pathol. 4:421-425.

Ferguson, G. P., Datta, A., Baumgartner, J., Roop, R. M., 2nd, Carlson, R. W., and Walker, G. C. 2004. Similarity to peroxisomal-membrane protein family reveals that Sinorhizobium and Brucella BacA affect lipid-A fatty acids. Proc. Natl. Acad. Sci. U.S.A. 101:5012-5017.

Ferguson, G. P., Datta, A., Carlson, R. W., and Walker, G. C. 2005 Importance of unusually modified lipid A in Sinorhizobium stress resistance and legume symbiosis. Mol. Microbiol. 56:68-80.

Floryszak-Wieczorek, J., Milczarek, G., Arasimowicz, M., and Ciszewski, A. 2006. Do nitric oxide donors mimic endogenous NO-related response in plants? Planta 224:1363-1372.

Foresi, N., Correa-Aragunde, N., Parisi, G., Caló, G., Salerno, G., and Lamattina, L. 2010. Characterization of a nitric oxide synthase from the plant kingdom: NO generation from the green alga Ostreococcus tauri is light irradiance and growth phase dependent. Plant Cell 22:38163830 .

Forouhar, F., Yang, Y., Kumar, D., Chen, Y., Fridman, E., Park, S. W., Chiang, Y., Acton, T. B., Montelione, G. T., Pichersky, E., Klessig, D. F., and Tong, L. 2005. Structural and biochemical studies identify tobacco SABP2 as a methyl salicylate esterase and implicate it in plant innate immunity. Proc. Natl. Acad. Sci. U.S.A. 102:1773-1778

Fujiwara, K., Iwanami, T., and Fujikawa, T. 2018. Alterations of Candidatus Liberibacter asiaticus-associated microbiota decrease survival of Ca. L. asiaticus in in vitro assays. Front. Microbiol. 9:3089.

Gabriel, D., Gottwald, T. R., Lopes, S. A., and Wulff, N. A. 2020. Bacterial pathogens of citrus: Citrus canker, citrus variegated chlorosis and Huanglongbing. Pages 371-389 in: The Genus Citrus, 1st Ed. M. Talon, M. Caruso, and F. Gmitter, eds. Woodhead Publishing, Elsevier, London, U.K.

Gao, Q. M., Yu, K., Xia, Y., Shine, M. B., Wang, C., Navarre, D., Kachroo, A., and Kachroo, P. 2014. Mono- and digalactosyldiacylglycerol lipids function nonredundantly to regulate systemic acquired resistance in plants. Cell Rep. 9:1681-1691.

Gaupels, F., Durner, J., and Kogel, K. H. 2017. Production, amplification and systemic propagation of redox messengers in plants? The phloem can do it all! New Phytol. 214:554-560.

Gottwald, T. R. 2010. Current epidemiological understanding of citrus huanglongbing. Annu. Rev. Phytopathol. 48:119-139.

Ha, P. T., He, R., Killiny, N., Brown, J. K., Omsland, A., Gang, D. R., and Beyenal, H. 2019. Host-free biofilm culture of "Candidatus Liberibacter asiaticus," the bacterium associated with huanglongbing. Biofilm 1:100005.

Horta, B. B., de Oliveira, M. A., Discola, K. F., Cussiol, J. R., and Netto, L. E. 2010. Structural and biochemical characterization of peroxiredoxin Qbeta from Xylella fastidiosa. J. Biol. Chem. 285:16051-16065.

Iizasa, S., Iizasa, E., Matsuzaki, S., Tanaka, H., Kodama, Y., Watanabe, K., and Nagano, Y. 2016. Arabidopsis LBP/BPI related-1 and -2 bind to LPS directly and regulate PRI expression. Sci. Rep. 6:27527. 
Iizasa, S., Iizasa, E., Watanabe, K., and Nagano, Y. 2017. Transcriptome analysis reveals key roles of AtLBR-2 in LPS-induced defense responses in plants. BMC Genomics 18:995.

Jain, M., Cai, L., Fleites, L. A., Munoz-Bodnar, A., Davis, M. J., and Gabriel, D. W. 2019a. Liberibacter crescens is a cultured surrogate for functional genomics of uncultured pathogenic 'Candidatus Liberibacter' spp. and is naturally competent for transformation. Phytopathology 109:1811-1819.

Jain, M., Fleites, L. A., and Gabriel, D. W. 2015. Prophage-encoded peroxidase in 'Candidatus Liberibacter asiaticus' is a secreted effector that suppresses plant defenses. Mol. Plant-Microbe Interact. 28:13301337.

Jain, M., Munoz-Bodnar, A., and Gabriel, D. W. 2019b. 'Candidatus Liberibacter asiaticus' peroxiredoxin (LasBCP) suppresses oxylipinmediated defense signaling in citrus. J. Plant Physiol. 236:61-65.

Jain, M., Munoz-Bodnar, A., Zhang, S., and Gabriel, D. W. 2018. A secreted 'Candidatus Liberibacter asiaticus' peroxiredoxin simultaneously suppresses both localized and systemic innate immune responses in planta. Mol. Plant-Microbe Interact. 31:1312-1322.

Jasid, S., Simontacchi, M., Bartoli, C. G., and Puntarulo, S. 2006. Chloroplasts as a nitric oxide cellular source. Effect of reactive nitrogen species on chloroplastic lipids and proteins. Plant Physiol. 142:12461255.

Jeandroz, S., Wipf, D., Stuehr, D. J., Lamattina, L., Melkonian, M., Tian, Z., Zhu, Y., Carpenter, E. J., Wong, G. K. S., and Wendehenne, D. 2016. Occurrence, structure, and evolution of nitric oxide synthaselike proteins in the plant kingdom. Sci. Signal. 9:re2.

Jung, H. W., Tschaplinski, T. J., Wang, L., Glazebrook, J., and Greenberg, J. T. 2009. Priming in systemic plant immunity. Science 324:89-91.

Kawai, T., and Akira, S. 2011. Toll-like receptors and their crosstalk with other innate receptors in infection and immunity. Immunity 34 637-650.

Killiny, N. 2017. Metabolite signature of the phloem sap of fourteen citrus varieties with different degrees of tolerance to Candidatus Liberibacter asiaticus. Physiol. Mol. Plant Pathol. 97:20-29.

Kim, J. S., Sagaram, U. S., Burns, J. K., Li, J. L., and Wang, N. 2009. Response of sweet orange (Citrus sinensis) to 'Candidatus Liberibacter asiaticus' infection: Microscopy and microarray analyses. Phytopathology 99:50-57.

Lee, J. A., Halbert, S. E., Dawson, W. O., Robertson, C. J., Keesling, J. E., and Singer, B. H. 2015. Asymptomatic spread of huanglongbing and implications for disease control. Proc. Natl. Acad. Sci. U.S.A 112:7605-7610.

Leonard, M. T., Fagen, J. R., Davis-Richardson, A. G., Davis, M. J., and Triplett, E. W. 2012. Complete genome sequence of Liberibacter crescens BT-1. Stand. Genomic Sci. 7:271-283.

Li, J., Pang, Z., Trivedi, P., Zhou, X., Ying, X., Jia, H., and Wang, N. 2017. 'Candidatus Liberibacter asiaticus' encodes a functional salicylic acid (SA) hydroxylase that degrades SA to suppress plant defenses. Mol. Plant-Microbe Interact. 30:620-630.

Li, W., Hartung, J. S., and Levy, L. 2006. Quantitative real-time PCR for detection and identification of Candidatus Liberibacter species associated with citrus huanglongbing. J. Microbiol. Methods 66:104-115.

Lindermayr, C., Sell, S., Müller, B., Leister, D., and Durner, J. 2010. Redox regulation of the NPR1-TGA1 system of Arabidopsis thaliana by nitric oxide. Plant Cell 22:2894-2907.

Lozano-Juste, J., Colom-Moreno, R., and León, J. 2011. In vivo protein tyrosine nitration in Arabidopsis thaliana. J. Exp. Bot. 62:3501-3517.

Malinverni, J. C., and Silhavy, T. J. 2009. An ABC transport system that maintains lipid asymmetry in the gram-negative outer membrane. Proc. Natl. Acad. Sci. U.S.A. 106:8009-8014.

Merfa, M. V., Pérez-López, E., Naranjo, E., Jain, M., Gabriel, D. W., and De La Fuente, L. 2019. Progress and obstacles in culturing 'Candidatus Liberibacter asiaticus', the bacterium associated with huanglongbing. Phytopathology 109:1092-1101.

Mhlongo, M. I., Tugizimana, F., Piater, L. A., Steenkamp, P. A., Madala, N. E., and Dubery, I. A. 2017. Untargeted metabolomics analysis reveals dynamic changes in azelaic acid- and salicylic acid derivatives in LPS-treated Nicotiana tabacum cells. Biochem. Biophys. Res. Commun. 482:1498-1503.

Mogensen, T. H. 2009. Pathogen recognition and inflammatory signaling in innate immune defenses. Clin. Microbiol. Rev. 22:240-273.

Molki, B., Call, D. R., Ha, P. T., Omsland, A., Gang, D. R., Lindemann, S. R., Killiny, N., and Beyenal, H. 2020. Growth of 'Candidatus Liberibacter asiaticus' in a host-free microbial culture is associated with microbial community composition. Enzyme Microb. Technol. 142: 109691.
Monger, W. A., and Jeffries, C. J. 2018. A survey of 'Candidatus Liberibacter solanacearum' in historical seed from collections of carrot and related Apiaceae species. Eur. J. Plant Pathol. 150:803-815.

Mur, L. A., Mandon, J., Persijn, S., Cristescu, S. M., Moshkov, I. E., Novikova, G. V., Hall, M. A., Harren, F. J., Hebelstrup, K. H., and Gupta, K. J. 2013. Nitric oxide in plants: An assessment of the current state of knowledge. AoB Plants 5:pls052.

Murashige, T., and Skoog, F. 1962. A revised medium for rapid growth and bioassays with tobacco tissue cultures. Physiol. Plant. 15:473-497.

Návarová, H., Bernsdorff, F., Döring, A. C., and Zeier, J. 2012. Pipecolic acid, an endogenous mediator of defense amplification and priming, is a critical regulator of inducible plant immunity. Plant Cell 24:5123-5141.

Nehela, Y., Hijaz, F., Elzaawely, A. A., El-Zahaby, H. M., and Killiny, N. 2018. Citrus phytohormonal response to Candidatus Liberibacter asiaticus and its vector Diaphorina citri. Physiol. Mol. Plant Pathol. 102:24-35.

Nehela, Y., and Killiny, N. 2019. 'Candidatus Liberibacter asiaticus' and its vector, Diaphorina citri, augment the tricarboxylic acid cycle of their host via the $\gamma$-aminobutyric acid shunt and polyamines pathway. Mol. Plant-Microbe Interact. 32:413-427.

Pang, Z., Zhang, L., Coaker, G., Ma, W., He, S. Y., and Wang, N. 2020. Citrus CsACD2 is a target of Candidatus Liberibacter asiaticus in huanglongbing disease. Plant Physiol. 184:792-805.

Raetz, C. R., Guan, Z., Ingram, B. O., Six, D. A., Song, F., Wang, X., and Zhao, J. 2009. Discovery of new biosynthetic pathways: The lipid A story. J. Lipid Res. 50:S103-S108.

Ranf, S. 2017. Sensing of molecular patterns through cell surface immune receptors. Curr. Opin. Plant Biol. 38:68-77.

Ranf, S., Gisch, N., Schäffer, M., Illig, T., Westphal, L., Knirel, Y. A., Sánchez-Carballo, P. M., Zähringer, U., Hückelhoven, R., Lee, J., and Scheel, D. 2015. A lectin S-domain receptor kinase mediates lipopolysaccharide sensing in Arabidopsis thaliana. Nat. Immunol. 16:426-433.

Reeves, S. A., Parsonage, D., Nelson, K. J., and Poole, L. B. 2011. Kinetic and thermodynamic features reveal that Escherichia coli BCP is an unusually versatile peroxiredoxin. Biochemistry 50:8970-8981.

Schwartz, A. R., Potnis, N., Timilsina, S., Wilson, M., Patané, J., Martins, J., Jr., Minsavage, G. V., Dahlbeck, D., Akhunova, A. Almeida, N., Vallad, G. E., Barak, J. D., White, F. F., Miller, S. A., Ritchie, D., Goss, E., Bart, R. S., Setubal, J. C., Jones, J. B., and Staskawicz, B. J. 2015. Phylogenomics of Xanthomonas field strains infecting pepper and tomato reveals diversity in effector repertoires and identifies determinants of host specificity. Front. Microbiol. 6:535.

Shang-Guan, K., Wang, M., Htwe, N. M. P. S., Li, P., Li, Y., Qi, F., Zhang, D., Cao, M., Kim, C., Weng, H., Cen, H., Black, I. M., Azadi, P., Carlson, R. W., Stacey, G., and Liang, Y. 2018. Lipopolysaccharides trigger two successive bursts of reactive oxygen species at distinct cellular locations. Plant Physiol. 176:2543-2556.

Sharypova, L. A., Niehaus, K., Scheidle, H., Holst, O., and Becker, A. 2003. Sinorhizobium meliloti acpXL mutant lacks the C28 hydroxylated fatty acid moiety of lipid A and does not express a slow migrating form of lipopolysaccharide. J. Biol. Chem. 278:12946-12954.

Silipo, A., Sturiale, L., Garozzo, D., Erbs, G., Jensen, T. T., Lanzetta, R., Dow, J. M., Parrilli, M., Newman, M. A., and Molinaro, A. 2008. The acylation and phosphorylation pattern of lipid A from Xanthomonas campestris strongly influence its ability to trigger the innate immune response in Arabidopsis. ChemBioChem 9:896-904.

Sun, T., Busta, L., Zhang, Q., Ding, P., Jetter, R., and Zhang, Y. 2018. TGACG-BINDING FACTOR 1 (TGA1) and TGA4 regulate salicylic acid and pipecolic acid biosynthesis by modulating the expression of SYSTEMIC ACQUIRED RESISTANCE DEFICIENT 1 (SARD1) and CALMODULIN-BINDING PROTEIN 60g (CBP60g). New Phytol. 217:344-354

Tada, Y., Spoel, S. H., Pajerowska-Mukhtar, K., Mou, Z., Song, J., Wang, C., Zuo, J., and Dong, X. 2008. Plant immunity requires conformational charges of NPR1 via S-nitrosylation and thioredoxins. Science 321:952-956.

Tanou, G., Ziogas, V., Belghazi, M., Christou, A., Filippou, P., Job, D., Fotopoulos, V., and Molassiotis, A. 2014. Polyamines reprogram oxidative and nitrosative status and the proteome of citrus plants exposed to salinity stress. Plant Cell Environ. 37:864-885.

Tavares, C. P., Vernal, J., Delena, R. A., Lamattina, L., Cassia, R., and Terenzi, H. 2014. S-nitrosylation influences the structure and DNA binding activity of AtMYB30 transcription factor from Arabidopsis thaliana. Biochim. Biophys. Acta 1844:810-817.

Thapa, S. P., De Francesco, A., Trinh, J., Gurung, F. B., Pang, Z., Vidalakis, G., Wang, N., Ancona, V., Ma, W., and Coaker, G. 2020. Genome-wide analyses of Liberibacter species provides insights into evolution, phylogenetic relationships, and virulence factors. Mol. Plant Pathol. 21:716-731. 
Thomas, D. D., Heinecke, J. L., Ridnour, L. A., Cheng, R. Y., Kesarwala, A. H., Switzer, C. H., McVicar, D. W., Roberts, D. D., Glynn, S., Fukuto, J. M., Wink, D. A., and Miranda, K. M. 2015. Signaling and stress: The redox landscape in NOS2 biology. Free Radic. Biol. Med. 87:204-225.

van der Burgh, A. M., and Joosten, M. H. A. J. 2019. Plant immunity: Thinking outside and inside the box. Trends Plant Sci. 24:587-601.

Vlot, A. C., Sales, J. H., Lenk, M., Bauer, K., Brambilla, A., Sommer, A., Chen, Y., Wenig, M., and Nayem, S. 2021. Systemic propagation of immunity in plants. New Phytol. 229:1234-1250.

Wang, C., Liu, R., Lim, G. H., de Lorenzo, L., Yu, K., Zhang, K., Hunt, A. G., Kachroo, A., and Kachroo, P. 2018. Pipecolic acid confers systemic immunity by regulating free radicals. Sci. Adv. 4:eaar4509.

Wimalasekera, R., Tebartz, F., and Scherer, G. F. 2011. Polyamines, polyamine oxidases and nitric oxide in development, abiotic and biotic stresses. Plant Sci. 181:593-603.

Wulff, N. A., Zhang, S., Setubal, J. C., Almeida, N. F., Martins, E. C., Harakava, R., Kumar, D., Rangel, L. T., Foissac, X., Bové, J. M., and Gabriel, D. W. 2014. The complete genome sequence of 'Candidatus Liberibacter americanus', associated with citrus huanglongbing. Mol. Plant-Microbe Interact. 27:163-176.
Xue, Y., Liu, Z., Gao, X., Jin, C., Wen, L., Yao, X., and Ren, J. 2010. GPS-SNO: Computational prediction of protein $S$-nitrosylation sites with a modified GPS algorithm. PLoS One 5:e11290.

Yu, K., Soares, J. M., Mandal, M. K., Wang, C., Chanda, B., Gifford, A. N., Fowler, J. S., Navarre, D., Kachroo, A., and Kachroo, P. 2013. A feedback regulatory loop between G3P and lipid transfer proteins DIR1 and AZI1 mediates azelaic-acid-induced systemic immunity. Cell Rep. 3:1266-1278.

Yun, B. W., Feechan, A., Yin, M., Saidi, N. B., Le Bihan, T., Yu, M. Moore, J. W., Kang, J. G., Kwon, E., Spoel, S. H., Pallas, J. A., and Loake, G. J. 2011. S-nitrosylation of NADPH oxidase regulates cell death in plant immunity. Nature 478:264-268.

Zhang, C., Du, P., Yan, H., Zhu, Z., Wang, X., and Li, W. 2020. A Secdependent secretory protein of the huanglongbing-associated pathogen suppresses hypersensitive cell death in Nicotiana benthamiana. Front. Microbiol. 11:3004.

Zoeller, M., Stingl, N., Krischke, M., Fekete, A., Waller, F., Berger, S. and Mueller, M. J. 2012. Lipid profiling of the Arabidopsis hypersensitive response reveals specific lipid peroxidation and fragmentation processes: Biogenesis of pimelic and azelaic acid. Plant Physiol. 160: $365-378$ 